\title{
Molecular etiology of arthrogryposis in multiple families of mostly Turkish origin
}

\begin{abstract}
Yavuz Bayram, ${ }^{1}$ Ender Karaca, ${ }^{1}$ Zeynep Coban Akdemir, ${ }^{1}$ Elif Ozdamar Yilmaz, ${ }^{2}$ Gulsen Akay Tayfun, ${ }^{3}$ Hatip Aydin, ${ }^{4}$ Deniz Torun, ${ }^{5}$ Sevcan Tug Bozdogan, ${ }^{6}$ Alper Gezdirici, ${ }^{7}$ Sedat Isikay, ${ }^{8}$ Mehmed M. Atik, ${ }^{1}$ Tomasz Gambin, ${ }^{1}$ Tamar Harel, ${ }^{1}$ Ayman W. El-Hattab, ${ }^{9}$ Wu-Lin Charng, ${ }^{1}$ Davut Pehlivan, ${ }^{1}$ Shalini N. Jhangiani, ${ }^{10}$ Donna M. Muzny, ${ }^{10}$ Ali Karaman, ${ }^{11}$ Tamer Celik, ${ }^{12}$ Ozge Ozalp Yuregir, ${ }^{13}$ Timur Yildirim, ${ }^{14}$ Ilhan A. Bayhan, ${ }^{14}$ Eric Boerwinkle, ${ }^{10,15}$ Richard A. Gibbs, ${ }^{10}$ Nursel Elcioglu, ${ }^{3}$ Beyhan Tuysuz, ${ }^{2}$ and James R. Lupski ${ }^{10,10,16,17}$

'Department of Molecular and Human Genetics, Baylor College of Medicine, Houston, Texas, USA. ²Department of Pediatric Genetics, Istanbul University Cerrahpasa Medical Faculty, Istanbul, Turkey. ${ }^{3}$ Department of Pediatric Genetics, Marmara University School of Medicine, Istanbul, Turkey. ${ }^{4}$ Department of Medical Biology, Namik Kemal University Medical Faculty, Tekirdag, Turkey. ${ }^{5}$ Department of Medical Genetics, Gulhane Military Medical Academy, Ankara, Turkey. ${ }^{6}$ Department of Medical Genetics, Mersin University Faculty of Medicine, Mersin, Turkey. ${ }^{7}$ Department of Medical Genetics, Kanuni Sultan Suleyman Training and Research Hospital, Istanbul, Turkey. ${ }^{8}$ Department of Pediatric Neurology, Kahramanmaras Sutcu Imam University, Kahramanmaras, Turkey. ${ }^{9}$ Division of Clinical Genetics and Metabolic Disorders, Department of Pediatrics, Tawam Hospital, Al-Ain, United Arab Emirates. ${ }^{10}$ Human Cenome Sequencing Center, Baylor College of Medicine, Houston, Texas, USA. "Center of Genetics Diagnosis, Zeynep Kamil Women's and Children's Diseases Training and Research Hospital, Istanbul, Turkey. ${ }^{2}$ Department of Pediatric Neurology, Adana Numune Research and Education Hospital, Adana, Turkey. ${ }^{13}$ Genetics Diagnosis Center, Seyhan Practice Center, Adana Numune Training and Research Hospital, Adana, Turkey. ${ }^{14}$ Orthopaedic and Traumatology Department, Baltalimani Bone Diseases Training and Research Hospital, Istanbul, Turkey. ${ }^{15}$ Human Genetics Center, University of Texas Health Science Center at Houston, Houston, Texas, USA. ${ }^{16}$ Department of Pediatrics, Baylor College of Medicine, Houston, Texas, USA. ${ }^{17}$ Texas Children's Hospital, Houston, Texas, USA.
\end{abstract}

BACKGROUND. Arthrogryposis, defined as congenital joint contractures in 2 or more body areas, is a clinical sign rather than a specific disease diagnosis. To date, more than $\mathbf{4 0 0}$ different disorders have been described that present with arthrogryposis, and variants of more than $\mathbf{2 2 0}$ genes have been associated with these disorders; however, the underlying molecular etiology remains unknown in the considerable majority of these cases.

METHODS. We performed whole exome sequencing (WES) of 52 patients with clinical presentation of arthrogryposis from 48 different families.

RESULTS. Affected individuals from 17 families (35.4\%) had variants in known arthrogryposis-associated genes, including homozygous variants of cholinergic $\gamma$ nicotinic receptor (CHRNG, 6 subjects) and endothelin converting enzyme-like 1 (ECEL1, 4 subjects). Deleterious variants in candidate arthrogryposis-causing genes (fibrillin 3 [FBN3], myosin IXA [MYO9A], and pleckstrin and Sec7 domain containing 3 [PSD3]) were identified in 3 families (6.2\%). Moreover, in 8 families with a homozygous mutation in an arthrogryposis-associated gene, we identified a second locus with either a homozygous or compound heterozygous variant in a candidate gene (myosin binding protein C, fast type [MYBPC2] and vacuolar protein sorting 8 [VPS8], 2 families, $4.2 \%$ ) or in another disease-associated genes ( 6 families, $12.5 \%$ ), indicating a potential mutational burden contributing to disease expression.

CONCLUSION. In $\mathbf{5 8 . 3 \%}$ of families, the arthrogryposis manifestation could be explained by a molecular diagnosis; however, the molecular etiology in subjects from 20 families remained unsolved by WES. Only 5 of these 20 unrelated subjects had a clinical presentation consistent with amyoplasia; a phenotype not thought to be of genetic origin. Our results indicate that increased use of genome-wide technologies will provide opportunities to better understand genetic models for diseases and molecular mechanisms of genetically heterogeneous disorders, such as arthrogryposis.

FUNDING. This work was supported in part by US National Human Genome Research Institute (NHGRI)/National Heart, Lung, and Blood Institute (NHLBI) grant U54HC006542 to the Baylor-Hopkins Center for Mendelian Cenomics, and US National Institute of Neurological Disorders and Stroke (NINDS) grant R01NS058529 to J.R. Lupski.

Conflict of interest: J.R. Lupski has stock ownership in 23andMe, is a paid consultant for Regeneron Pharmaceuticals, has stock options in Lasergen Inc., and is a coinventor on multiple US and European patents related to molecular diagnostics for inherited neuropathies, eye diseases, and bacterial genomic fingerprinting. The Department of Molecular and Human Genetics at Baylor College of Medicine derives revenue from the chromosomal microarray analysis (CMA) and clinical exome sequencing offered in the Baylor Miraca Genetics Laboratory (BMGL, http://www.bmgl.com/BMGL/Default.aspx). R.A. Gibbs is interim Chief Scientific Officer of BMCL, and J.R. Lupski is on the Scientific Advisory Board of BMGL. Submitted: August 27, 2015; Accepted: November 25, 2015.

Reference information: / Clin Invest. 2016;126(2):762-778. doi:10.1172/JCI84457.

\section{Introduction}

Arthrogryposis, also known as arthrogryposis multiplex congenita, is clinically defined as congenital joint contractures or movement restriction in multiple body areas. It should be distinguished from isolated congenital contractures that affect a single joint such as congenital clubfoot deformity or dislocated hip. Arthrogryposis is a symptom rather than a specific diagnosis and occurs in between $1 / 3,000-1 / 5,000$ live births (1). To date, more 
than 400 disorders have been described that include arthrogryposis as an endophenotype (2).

In general, arthrogryposis occurs by virtue of a secondary effect of decreased fetal joint mobility (i.e., fetal akinesia). Disorders leading to fetal akinesia can result from abnormalities of the CNS, neuromuscular system, skeletal system, and connective and cartilage tissue disturbances. Maternal diseases or environmental factors such as intrauterine space limitations, maternal exposures to drugs or chemicals, compromise of blood supply to the fetus, and metabolic disturbances may also lead to fetal akinesia (2-4).

Distal arthrogryposis (DA) syndromes describe a heterogeneous subgroup of arthrogryposis characterized by multiple congenital contractures that mainly involve the distal parts of the upper and lower limbs without a primary neuromuscular disease $(5,6)$. According to different classifications, up to 19 clinical subtypes of DA were described $(2,5,7)$. In most cases $(-50 \%)$, mutations in genes encoding contractile proteins of skeletal muscles were shown to cause the DA phenotype, which consists of nonprogressive congenital contractures of the joints located at distal limbs (8-12). Genes determined to contribute to the molecular etiology of DA include FBN2, MYBPC1, MYH3, MYH8, PIEZO2, TNNI2, TNNT3, and TPM2. Recently, homozygous ECEL1 mutations, most representing loss-of-function alleles and resulting in absence of the encoded protein, were identified in patients with DA type 5D (OMIM 615065). In this group of DA, patients presented a distinctive clinical presentation with severe camptodactyly of the hands and wrists; milder camptodactyly of toes; limited knee flexion; talus and/or varus deformity of the ankles; ptosis and distinctive facial features of round-shaped, mask-like faces; higharched eyebrows; bulbous noses; and micrognathia $(13,14)$.

Another phenotypically and genetically heterogeneous subgroup of arthrogryposis is multiple pterygium syndrome (MPS), which is characterized by multiple pterygia, scoliosis, and congenital contractures of the limbs. MPS has both lethal (OMIM 253290) and nonlethal (Escobar variant) (OMIM 265000) types. Although most of the MPS cases were reported with a pattern of autosomal-recessive inheritance (15), autosomal-dominant transmission was also observed in a few cases (16-18). While homozygous and compound heterozygous mutations of CHRNG $(19,20)$ were associated with both lethal and nonlethal types of MPS, mutations of CHRND (21) and CHRNA1 (21) are also responsible for lethal MPS. Recently, homozygous mutations in RYR1 (22) and autosomal-dominant inheritance with $M Y H 3$ mutations were reported in MPS patients (23).

Genetic causes of disorders with arthrogryposis include single gene mutations, chromosomal abnormalities, and mitochondrial defects $(2,24,25)$. To date, variants in more than 220 genes with different modes of inheritance have been associated with arthrogryposis disorders (Supplemental Table 1; supplemental material available online with this article; doi:10.1172/JCI84457DS1), but in the considerable majority of these disorders, the underlying molecular etiology remains unknown. To better understand the genetics of arthrogryposis and identify potential novel molecular etiologies underlying this genetically heterogeneous group of diseases, we applied whole exome sequencing (WES) to a cohort of 52 patients from 48 families, including 22 with reported consanguinity yet with different clinical subtypes of arthrogryposis.

\section{Results}

The approach used for gene identification is outlined in Supplemental Figure 1. We first assessed WES data of all patients for rare variants in known arthrogryposis genes before investigating for potential novel genes. A list of known genes (Supplemental Table 1) was constructed from multiple online database resources (http:// www.omim.org/, http://www.mnglabs.com/tests/, http://www. ncbi.nlm.nih.gov/pubmed) or abstracted from recently published articles (2, 3, 26-35). Deleterious variants in the known arthrogryposis-associated genes were identified in 17 of 48 (35.4\%) unrelated families (Table 1). To the best of our knowledge, specific rare variants in known genes were not reported previously in 12 of 17 families, and 3 of those (CENPJ, GBE1, and IDS) were associated with traits suggesting phenotypic expansion (Table 1). In 3 families (6.2\%), we identified deleterious variants in 3 novel genes, including FBN3, MYO9A, and PSD3. In 8 families (16.7\%), we describe a second homozygous or compound heterozygous variant in a novel gene or in another known gene, in addition to the homozygous variant in a known gene (vacuolar protein sorting 8 [VPS8 (novel)] with POLR3A, MYBPC2 [novel] with GPR126, CHRNG with ERCC2, COL6A3 with BICD2, LIFR with PI4KA, LIFR with MYH14, MYO18B with MYH7B, and RIPK4 with LMNA) (Table 2). Identified variants in these apparently solved cases with a molecular diagnosis obtained from WES and family pedigrees are provided in Supplemental Table 2 and Supplemental Figure 2, respectively.

While $58.3 \%$ of families manifesting arthrogryposis could be explained by a molecular diagnosis identified on WES, subjects from 20 families remained unsolved, in that no definitive molecular diagnosis could be concluded. Since amyoplasia is the most common form of arthrogryposis that appears to be a sporadic nongenetic condition, we have carefully reexamined the clinical information of the patients in the 20 unsolved families. Five of these indeed match the clinical diagnosis of amyoplasia. However, the remaining 15 probands had different types of arthrogryposisrelated disorders, such as spinal muscular atrophy, DA, MPS, and other unspecified multiple joint contractures. There were no disease-causing variants in known genes in these patients, and we could not identify any variant in a novel gene with convincing supporting data. Thus, we concluded that $5 / 20$ unsolved cases had a clinical presentation consistent with amyoplasia, providing a possible explanation as to why no molecular diagnosis was achieved, at least in these cases.

We identified 1 homozygous stop-gain (in 2 families) and 2 homozygous missense mutations in ECEL1 in 4 unrelated consanguineous families, one of which is an Arab family (HOU2530). In 2 unrelated Turkish families (HOU1530 and HOU2432) with DA, we identified the same homozygous stop-gain mutation in ECEL1 (c.1147C > T; p.Gln383X). In addition, for 2 unrelated consanguineous families (HOU2460 and HOU2530), we detected 2 different homozygous missense ECEL1 mutations (c.2023G >A; p.Ala675Thr and c.1210C $>\mathrm{T}$; p.Arg404Cys, respectively [Figure 1A]).

From a clinical perspective, patient BAB3934 from family HOU1530 had contractures of both hands and feet, limited knee flexion, and bilateral hip dislocation. Electromyelography (EMG) study revealed mild myogenic involvement. The subject had a flat and round-shaped face, high-arched eyebrows, and a bulbous and upturned nose. Clinical findings of the patient BAB6500 from 


\section{Table 1. Patients with a rare mutation in a single known gene}

\begin{tabular}{|c|c|c|c|c|c|c|c|}
\hline Pedigree & Patient & Clinical findings & Gene & Variant & $\begin{array}{c}\text { Novel } \\
\text { variant }\end{array}$ & Zyg & Gene-Phenotype relationship(s) \\
\hline HOU1684 & BAB4104 & $\begin{array}{l}\text { Contractures of elbows and knees, camptodactyly, syndactyly of left } \\
\text { toes } 3 \text { and } 4 \text {, overlapping fingers and toes, rocker-bottom feet, } \\
\text { bilateral pitosis, microganthia, short and webbed neck, } \\
\text { hypospadias, and bilateral cryptorchidism }\end{array}$ & CHRNG & $\begin{array}{l}\text { c. } 256 C>T ; \\
\text { p.Arg86Cys }\end{array}$ & Yes & Hom & \multirow{4}{*}{$\begin{array}{l}\text { MPS, lethal type (OMIM 253290); } \\
\text { Escobar syndrome (OMIM 26500) }\end{array}$} \\
\hline HOU2430 & BAB6498 & $\begin{array}{l}\text { Contractures of hands, elbows, and knees; multiple pterygiums; } \\
\text { short neck; TEV; DPF; small mouth; and decayed teeth }\end{array}$ & CHRNG & $\begin{array}{l}\text { c.753_-754 delcT; } \\
\text { p.Val253fs }\end{array}$ & No & Hom & \\
\hline HOU2331 & BAB6209 & $\begin{array}{l}\text { Contractures of hands, elbows, and knees; multiple pterygiums; } \\
\text { talipes valgus; small and low-set ears; micrognathia; } \\
\text { and ambiguous genitalia }\end{array}$ & CHRNG & $\begin{array}{c}\text { c.715C>T; } \\
\text { p.Arg239Cys }\end{array}$ & No & Hom & \\
\hline HOU2607 & BAB7083 & $\begin{array}{l}\text { Contractures of elbows and knees, short neck, camptodactyly, } \\
\text { TEV, micrognathia, and prominent ears }\end{array}$ & CHRNG & $\begin{array}{l}\text { c.715C>T; } \\
\text { p.Arg239Cys }\end{array}$ & No & Hom & \\
\hline HOU2460 & BAB6608 & $\begin{array}{l}\text { Contracture of elbows, camptodactyly, scoliosis, ptosis, flat and mask-like face, } \\
\text { high-arched eyebrows, low-set ears, micrognathia, and cryptorchidism }\end{array}$ & ECEL1 & $\begin{array}{l}\text { c.2023G>A; } \\
\text { p.Ala675Thr }\end{array}$ & No & Hom & \multirow[t]{2}{*}{ DA type 5D (0MIM 615065) } \\
\hline HOU2530 & BAB6827 & $\begin{array}{l}\text { Severe camptodactyly, hip dislocation, hypotonia, right TEV, developmental } \\
\text { delay, thin corpus callosum on cranial MRI, mask-like face, } \\
\text { high-arched eyebrows, bulbous and upturned nose, low-set ears, } \\
\text { micrognathia, nephrocalcinosis, and cryptorchidism }\end{array}$ & ECEL1 & $\begin{array}{l}\text { c.1210C>T; } \\
\text { p.Arg404Cys }\end{array}$ & No & Hom & \\
\hline
\end{tabular}

Contractures of both hands, TEV, high-arched feet,
and contracture of toes
Contractures of both hands, TEV, high-arched feet,
and contracture of toes

$\begin{array}{lll}\text { COL6A2 } & \text { c.289G }>A ; \\ & \text { p.Ala97Thr }\end{array}$ Yes Hom

Myosclerosis, congenital (OMIM 255600); Bethlem myopathy (OMIM 158810); Ullrich congenital muscular dystrophy (OMIM 254090)

\begin{tabular}{|c|c|c|c|c|c|c|c|}
\hline HOU1529 & ВАВ3931 & $\begin{array}{l}\text { Contractures of elbows, ulnar deviation of hands, retromicrognathia, } \\
\text { high-arched palate, crowded and decayed teeth, low-set ears, delayed } \\
\text { bone age, TEV, and abnormal scar formation on left foot }\end{array}$ & $(E N P)^{\mathrm{A}}$ & $\begin{array}{l}\text { c.763A>G; } \\
\text { p.Thr255Ala }\end{array}$ & Yes & Hom & $\begin{array}{l}\text { Microcephaly 6, primary, autosomal } \\
\text { recessive (OMIM 608393); SCKL } 4 \\
\text { (OMIM 613676) }\end{array}$ \\
\hline HOU1539 & BAB3955 & $\begin{array}{l}\text { Flexion contractures of hands, rocker-bottom feet, delayed neuromotor } \\
\text { development, growth retardation, hypotonia, seizures, low-set ears, high-arched } \\
\text { palate, laryngomalacia, AP-US: Hepatosteatosis and nephrocalcinosis, EEG: } \\
\text { Hypsarrhythmia, and EMG: Anterior horn cell involvement of spinal cord. } \\
\text { Died at } 1.5 \text { years. Clinical diagnosis: Spinal muscular atrophy }\end{array}$ & $I D S^{A}$ & $\begin{array}{l}\text { c.613G>A; } \\
\text { p.Ala205Thr }\end{array}$ & Yes & Hem & MPS2 (OMIM 309900) \\
\hline HOU1541 & ВАВ3960 & $\begin{array}{l}\text { Joint contractures, hypotonia, cleft palate, micrognathia, short neck, tall } \\
\text { vertebral bodies on X-ray, mild talipes equinovarus, and pelvicaliectasis }\end{array}$ & $C B E 1^{A}$ & $\begin{array}{l}\text { c.776C >G; } \\
\text { p.Ala259Gly }\end{array}$ & Yes & Hom & $\begin{array}{l}\text { Clycogen storage disease IV (OMIM } \\
\text { 232500); Polyglucosan body disease, } \\
\text { adult form (OMIM 263570) }\end{array}$ \\
\hline HOU2114 & BAB5449 & $\begin{array}{l}\text { Elbow contractures, developmental delay, recurrent infections, swallowing } \\
\text { difficulty, contractures of the facial muscles, chubby cheeks, blepharophimosis, } \\
\text { epicanthal folds, synophrys, long eyelashes, hirsutism, prominent and wide } \\
\text { nasal root, high-arched palate, small mouth, and severe dental caries }\end{array}$ & CRLF1 & $\begin{array}{c}\text { c.984_985insG; } \\
\text { p.Ser328fs }\end{array}$ & Yes & Hom & $\begin{array}{l}\text { Cold-induced sweating syndrome } 1 \\
\text { (OMIM 272430) }\end{array}$ \\
\hline HOU2789 & BAB7707 & $\begin{array}{l}\text { Contractures of elbows and hands, patella agenesis, short stature, } \\
\text { pectus carinatum, epiphyseal and metaphysial dysplasia, } \\
\text { mild TEV, and delayed motor milestones }\end{array}$ & SLC26A2 & $\begin{array}{l}\text { c.2057C>A; } \\
\text { p.Cys686Tyr }\end{array}$ & Yes & Hom & $\begin{array}{l}\text { Diastrophic dysplasia (OMIM } \\
\text { 222600); Atelosteogenesis } 2 \text { (OMIM } \\
\text { 256050); Achondrogenesis 1B (OMIM } \\
\text { 600972); Epiphyseal dysplasia, } \\
\text { multiple, } 4 \text { (OMIM 226900) }\end{array}$ \\
\hline
\end{tabular}

${ }^{A}$ Cenes in which variant alleles were associated with traits suggesting phenotypic expansion. AD, autosomal dominant; AP-US, abdominopelvic ultrasound; DPF, downslanting palpebral fissures; ECHO, echocardiogram; EEG, electroencephalography; Hem, hemizygous; Hom, homozygous; TEV, talipes equinovarus; Zyg, zygosity. 


\section{Table 2. Clinical and genotype summary of the patients with potential oligogenic or mutational burden model}

\begin{tabular}{|c|c|c|c|c|c|c|}
\hline Pedigree & Patient & Clinical findings & Gene & Variant & Zyg & Gene-Phenotype relationship(s) \\
\hline HOU2163 & BAB5611 & $\begin{array}{l}\text { Terminated pregnancy at } 24 \text { weeks of gestation. } \\
\text { Fetal autopsy: Joint contractures, depressed nasal root, } \\
\text { micrognathia, lung hypoplasia, short thorax, } \\
\text { and rocker-bottom feet }\end{array}$ & CHRNG & c.1775G>A; p.Arg592His & Hom & $\begin{array}{l}\text { MPS, lethal type (OMIM 253290), } \\
\text { Escobar syndrome (OMIM 26500) }\end{array}$ \\
\hline \multirow[t]{3}{*}{ HOU2278 } & BAB6018 & $\begin{array}{l}\text { Contractures of knees and elbows, developmental delay, } \\
\text { hip dislocation, torticollis, scoliosis, pes planus, } \\
\text { micrognathia, anteverted nostrils, high-arched palate, } \\
\text { prominent ears, brain MRI: ventricular dilatation } \\
\text { and brain stem atrophy }\end{array}$ & COLGA3 & c.7720delc; p.Leu2574fs & Hom & $\begin{array}{l}\text { Bethlem myopathy (OMIM 158810); Ullrich } \\
\text { congenital muscular dystrophy (OMIM 254090) }\end{array}$ \\
\hline & \multirow{2}{*}{ BAB6019 } & \multirow{2}{*}{$\begin{array}{l}\text { Mild joint contractures, developmental delay, } \\
\text { hip dislocation, scoliosis, flat occiput, micrognathia, } \\
\text { anteverted nostrils, high-arched palate, and macrotia }\end{array}$} & COLGA3 & c.7720delc; p.Leu2574fs & Hom & $\begin{array}{l}\text { Bethlem myopathy (OMIM 158810); Ullrich } \\
\text { congenital muscular dystrophy (OMIM 254090) }\end{array}$ \\
\hline & & & $B I C D 2$ & c.1477C>T; p.Arg493Сys & Het & $\begin{array}{l}\text { Spinal muscular atrophy, lower extremity } \\
\text { predominant, 2, AD (OMIM 615290) }\end{array}$ \\
\hline HOU2682 & BAB7302 & $\begin{array}{l}\text { Contractures of distal joints, delayed neuromotor } \\
\text { development, hypotony, swallowing difficulty, } \\
\text { pyloric stenosis, tibia vara, enlarged metaphyses, } \\
\text { and multiple milia }\end{array}$ & PI4KA & c.1901T>c; p.Met634Thr & Hom & $\begin{array}{l}\text { Recently associated with perisylvian } \\
\text { polymicrogyria, cerebellar hypoplasia and } \\
\text { arthrogryposis (33) }\end{array}$ \\
\hline HOU2616 & BAB7125 & $\begin{array}{l}\text { Contractures of hands and elbows, severe } \\
\text { developmental delay, swallowing difficulty, high-arched } \\
\text { palate, pectus excavatum, scoliosis, hypertrophy in calf } \\
\text { muscles, and mild mitral valve insufficiency }\end{array}$ & $\begin{array}{l}\text { MYH14 } \\
\text { MYH14 }\end{array}$ & c.5887C>T; p.Arg1963Сys & Hom & $\begin{array}{l}\text { Peripheral neuropathy, myopathy, hoarseness, } \\
\text { and hearing loss (OMIM 614369); deafness, } \\
\text { autosomal dominant 4A (OMIM 600652) }\end{array}$ \\
\hline \multirow[b]{2}{*}{ HOU2791 } & \multirow[b]{2}{*}{ BAB7713 } & \multirow[b]{2}{*}{$\begin{array}{l}\text { Contractures of hands and feet, TEV, hypotony, } \\
\text { myopathic face, feeding difficulty, EMG: myopathia, } \\
\text { ECHO: dilated cardiomyopathy }\end{array}$} & RIPK4 & c.1681G>A; p.Val561Met & Hom & $\begin{array}{l}\text { Popliteal pterygium syndrome 2, lethal type } \\
\text { (OMIM 263650) }\end{array}$ \\
\hline & & & LMNA & c.350A>G; p.Lys117Arg & Hom & $\begin{array}{l}\text { Cardiomyopathy, dilated, 1A (OMIM 115200); } \\
\text { Emery-Dreifuss muscular dystrophy 3, AR } \\
\text { (OMIM 181350); Heart-hand syndrome, } \\
\text { Slovenian type (OMIM 610140); Muscular } \\
\text { dystrophy, congenital (OMIM 613205); } \\
\text { Muscular dystrophy, limb-girdle, } \\
\text { type 1B (OMIM 159001) }\end{array}$ \\
\hline
\end{tabular}

$A D$, autosomal dominant; $A R$, autosomal recessive; ECHO, echocardiogram; Het, heterozygous, Hom: homozygous; TEV, talipes equinovarus.

family HOU2432 included flexion contractures of both hands, hipjoint dysplasia, talipes valgus, and also a unique facial dysmorphic feature of a flat and round-shaped face with a mask-like whistling appearance (Figure 1B). After a careful search within the kindred in HOU2432, a third-degree cousin of BAB6500 was also found to have DA. The affected cousin and his parents were analyzed by
Sanger sequencing, and the cousin was also found to be homozygous while the parents were heterozygous carriers for the same variant identified in BAB6500 (Figure 1A).

Individual BAB6608 from family HOU2460 had contractures of the elbows, camptodactyly, scoliosis, ptosis, a flat and mask-like face, high-arched eyebrows, low-set ears, micrognathia, 
and cryptorchidism. Individual BAB6827 from family HOU2530 had severe camptodactyly of the hands, bilateral hip dislocation, right talipes equinovarus, hypotonia, developmental delay, cryptorchidism, nephrocalcinosis detected in the sonogram of the abdomen, and thin corpus callosum. He also had distinctive facial features of a mask-like face, high-arched eyebrows, a bulbous and upturned nose, low-set ears, and micrognathia (Figure 1B). Moreover, given the consanguinity between the parents in these 4 families, we examined the absence of heterozygosity $(\mathrm{AOH})$ regions in all probands with ECEL1 mutations. Haplotype block analysis based on single nucleotide polymorphism data culled from exome sequencing (i.e., B-allele frequency) revealed that the maximal shared region of $\mathrm{AOH}$ in the 4 families was approximately 840 $\mathrm{Kb}$ on the distal long arm of chromosome 2, including the ECEL1 gene. Since there are 3 different mutations, the actual haplotypes in these $\mathrm{AOH}$ blocks are presumed to differ (Figure 1C).

In 6 patients, we identified 4 different homozygous variants in CHRNG, a known causal gene for lethal and nonlethal MPS. The identified variants include 1 stop-gain (c.241C>T; p.Gln81X), 1 frameshift deletion (c.753_754delCT; p.Val253Alafs), 1 missense mutation (c.256C>T; p.Arg86Cys), and 1 recurrent missense mutation (c.715C $>\mathrm{T}$; p.Arg239Cys), which was observed in 3 patients from reportedly unrelated families (Figure 2A). The common findings in these patients were prenatally detected restriction of movements; craniofacial dysmorphisms, including down-slanting palpebral fissures, low-set ears, and micrognathia; and multiple contractures of the limbs (Figure 2B). The distribution of CHRNG mutations detected in our study is shown in Figure 2, C and D. Two of the identified CHRNG mutations have not been reported, while the other mutations, including the recurrent mutation, have been reported previously in MPS patients (20, 36). In 1 of 3 patients with the same homozygous CHRNG mutation (BAB5611), we additionally identified another homozygous deleterious mutation in a different arthrogryposis gene, ERCC2 (c.1775G>A; p.Arg592His) (Figure 2A). ERCC2 is a known gene for an arthrogryposis related disorder, cerebrooculofacioskeletal syndrome (COFS) type 2 (OMIM 610756), and 2 other allelic disorders (trichothiodystrophy [OMIM 601675] and xeroderma pigmentosum, group D [OMIM 278730]).

Other identified variants in known genes are delineated in Tables 1 and 2. Although 17 of these families are singleton cases with different mutations in different known genes (Table 1), we observed 8 families with an arthrogryposis gene mutational load, as we observed in family HOU2163 with CHRNG and ERCC2 mutations (Table 2). These families have another homozygous or compound heterozygous predicted deleterious variant in an additional known gene or in a novel gene that cannot be excluded from having a potential clinical contribution because of its function in arthrogryposis formation or close interactions with known arthrogryposis gene products.

After exclusion of known genes, we examined patient genomes for novel genes, investigating all potential inheritance models. Our strategy of choosing best-candidate genes was based on function of the gene; interactions with other known arthrogryposis genes; functional prediction scores calculated by different computational algorithms (PolyPhen-2, MutationTaster, SIFT, LRT, and Phylop); review of our internal database $(\sim 4,800$ exomes), including the Turkish subpopulation ( 630 exomes), or other available databases such as the 1,000 Genomes Project (http:// www.1000genomes.org), the Exome Variant Server, NHLBI GO Exome Sequencing Project (ESP; Seattle, Washington, USA; http://evs.gs.washington.edu/EVS/), the Atherosclerosis Risk in Communities Study (ARIC) database (http://drupal.cscc.unc.edu/ aric/), and the Exome Aggregation Consortium (ExAC, http:// exac.broadinstitute.org/) databases to examine the rarity of the identified variants; and segregation in the family studied. Using this approach, we identified compound heterozygous variants in FBN3 (c.1883C>T; p.Ser628Phe and c.8357G>A; p.Gly2786Asp) in a patient with contractions of the elbows and knees, compound heterozygous variants in MYO9A (c.6845G>A; p.Gly2282Glu and c.608A>G; p.Tyr203C) in a patient with multiple limb contractures, and a heterozygous missense PSD3 variant (c.437T $>C$; p.Ile146Thr) in 3 affected kindred with antecubital pterygium syndrome (APS) (OMIM 178200) (Table 3).

\section{Discussion}

In our study, we define a general approach to investigate the molecular etiology underlying arthrogryposis by using WES in a patient cohort of subjects with different clinical subtypes of arthrogryposis. We identified known and novel variants in known genes and variants in potential novel candidate genes, and we provide evidence for phenotypic expansion in a few cases. Moreover, some subjects were found to have evidence for an apparent mutational load with disease-associated variants in more than one arthrogryposis gene locus and to be manifesting a more severe clinical phenotype.

The most common known arthrogryposis-associated genes identified in our cohort were ECEL1 and CHRNG. While the phenotypes associated with these variants were overall consistent with those reported, some patients had novel clinical features. For instance, BAB6500 had a distinct whistling face, which is commonly observed with $M Y H 3$ variants in Freeman-Sheldon syndrome (also known as DA type 2A) (OMIM 193700) (9). MYH3 encodes one of the contractile proteins of skeletal muscle, while ECEL1 mutations result in perturbed formation of the neuromuscular junction. Although developmental pathways that cause DA type 2A and DA type 5D are different, the observed whistling-face finding in an ECEL1 mutated case not only shows the complexity of the phenotypic spectrum seen in this heterogeneous subgroup of arthrogryposis, but also underscores the limitation of clinical characterization of arthrogryposis subtypes. Patient BAB6827 had hypoplasia of the corpus callosum (HCC), in addition to DA. Given the functional and expression patterns of ECEL1 in conjunction with neurologic findings in the patient (i.e., developmental delay and hypotonia), it is feasible to suggest that HCC may be part of the phenotype. Alternatively, there may be a yet unidentified second molecular diagnosis in this patient.

Families consistent with a potential oligogenic or mutational burden model. In patient BAB5611, a homozygous variant in ERCC2 was detected, in addition to a homozygous variant in CHRNG (Figure 2A). Mutations in ERCC2 have previously been reported in patients with COFS type 2 (37), a progressive neurodegenerative and arthrogryposis-related disorder. Vogt et al. and Morgan et al. reported a family with a homozygous missense CHRNG mutation; 2 affected siblings died in early infancy, while the third 
A
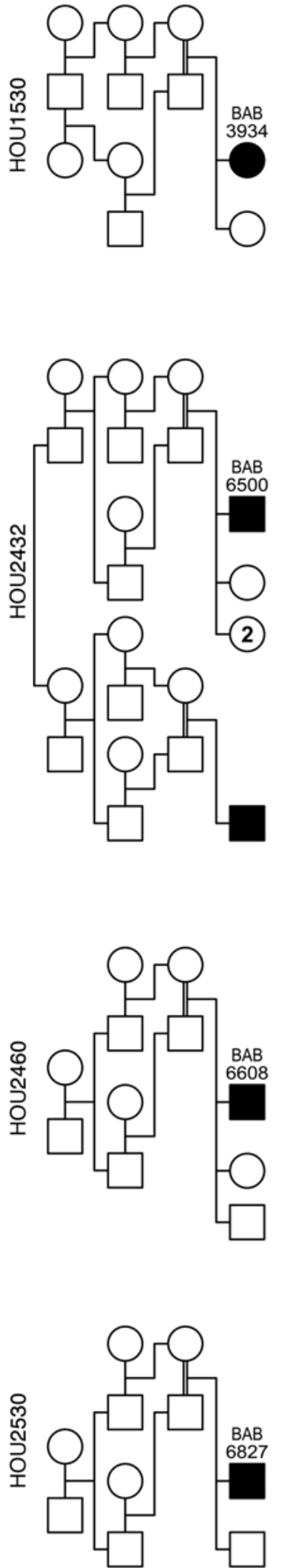

ECEL1 - c.1147C>T ¿ CATGCFAGCA ¿ WNWWW CATGS TAGCA 昰 MNlWWD CATGTAGCA 응 Mlllwa 这 CATG /AGCA क MNWWM

ECEL1 - c.1147C>T DATGCAGCA ¿ MNWWW DATGCTAGCA 昰 MNIWWD catGTAGCA ․ㅡㄴ WNhWM CATGCYAGCA एँ MNWWM ¿ MATG ¿AGCA CATGCAAGCA 胥 WNhWM 들 CATAGCA 음 Whllow

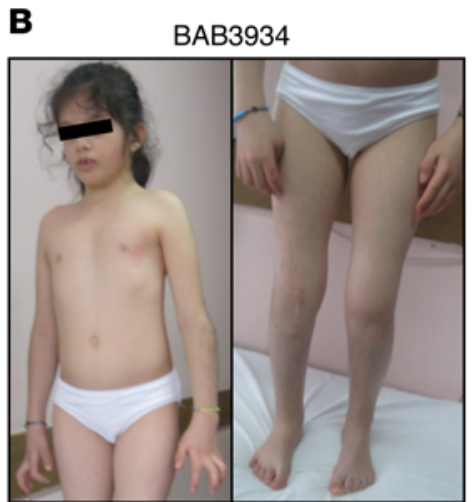

C
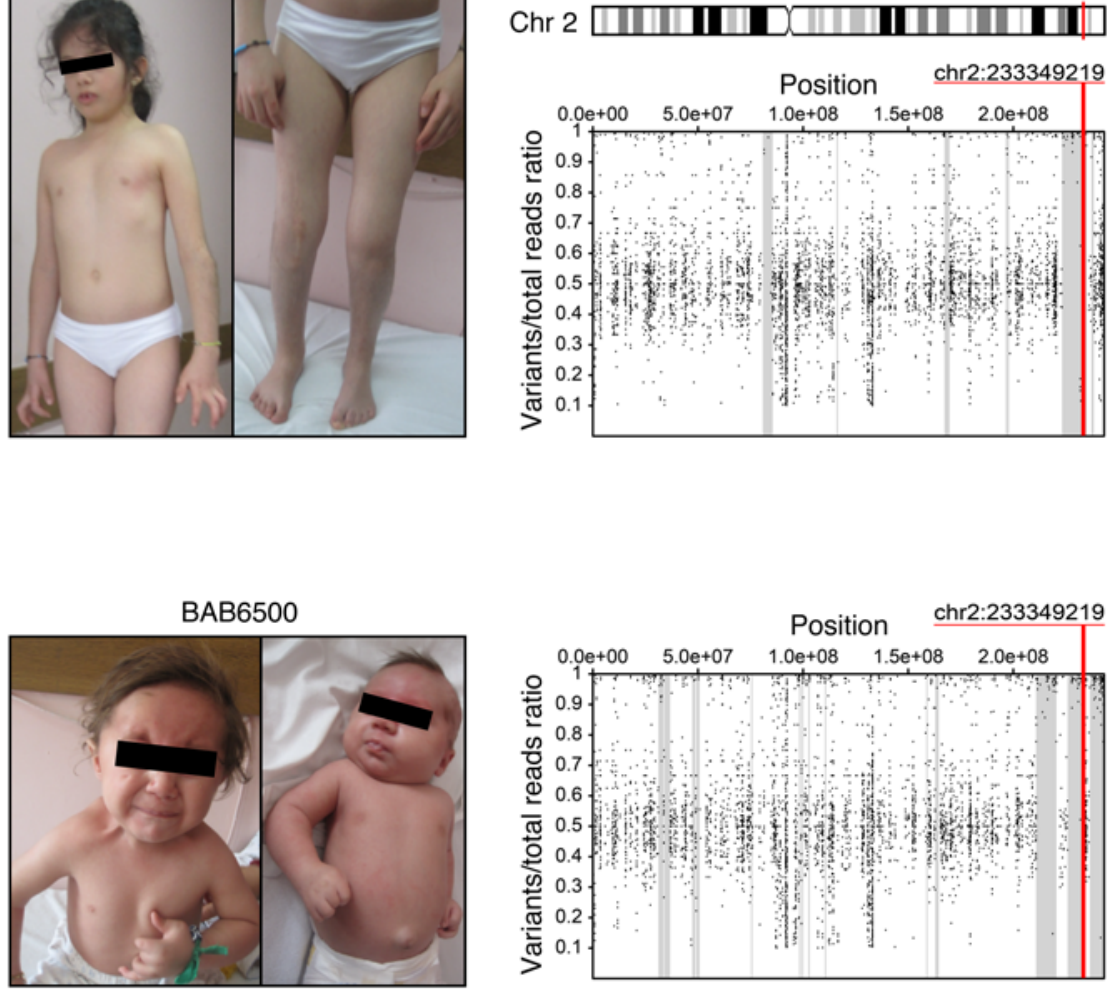

ECEL1 - c.2023G>A ¿ CATC $\%$ CAGA

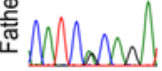
- CATCACAGA 응 M.MWMW CATC $\%$ CAGA

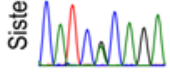
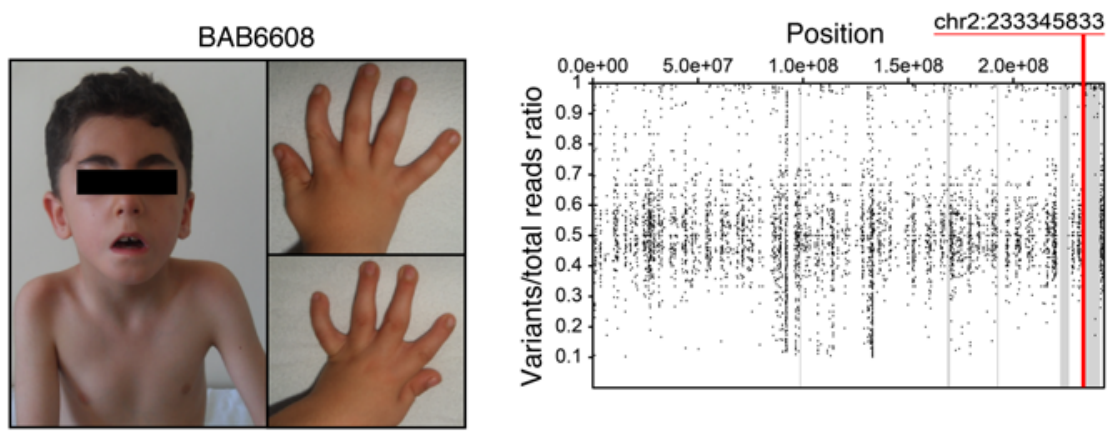

ECEL1 - c. $1210 C>T$
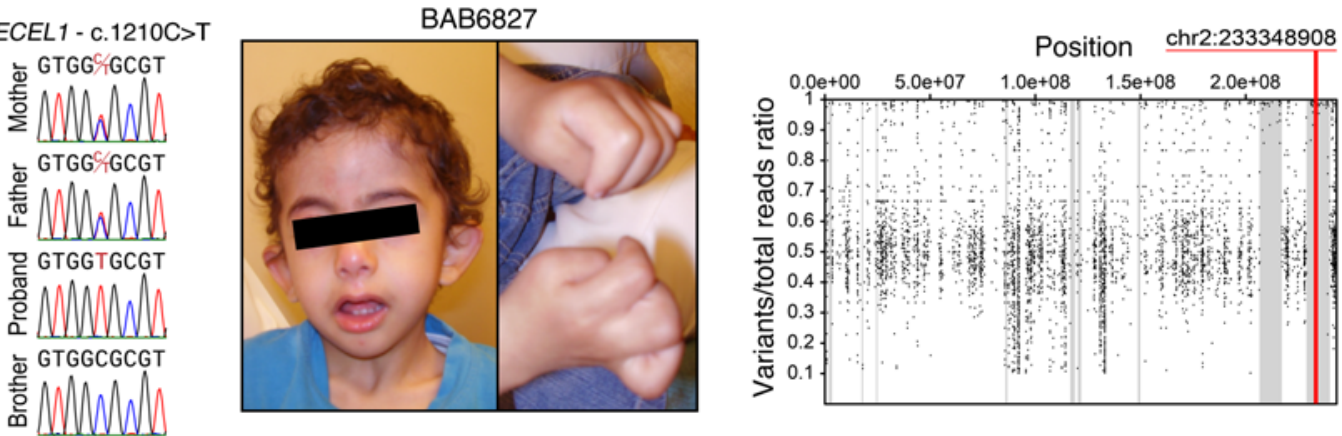

Figure 1. Segregation analyses, photographs, and AOH regions of the patients with ECEL1 mutations. (A) Detailed pedigrees of the families and their corresponding Sanger-sequencing chromatograms showing the segregation analyses. (B) Photographs of the patients. Note the whistling-face appearance of BAB6500, which is commonly observed in DA type 2A rather than ECEL1-associated DA type 5D. (C) AOH study of the patients based on calculated $\mathrm{B}$-allele frequency data culled from WES analysis. Gray shaded areas indicate $\mathrm{AOH}$ regions. Note the approximately $840-\mathrm{Kb}$ overlap between the $\mathrm{AOH}$ regions, which includes the ECEL1 gene. 
A
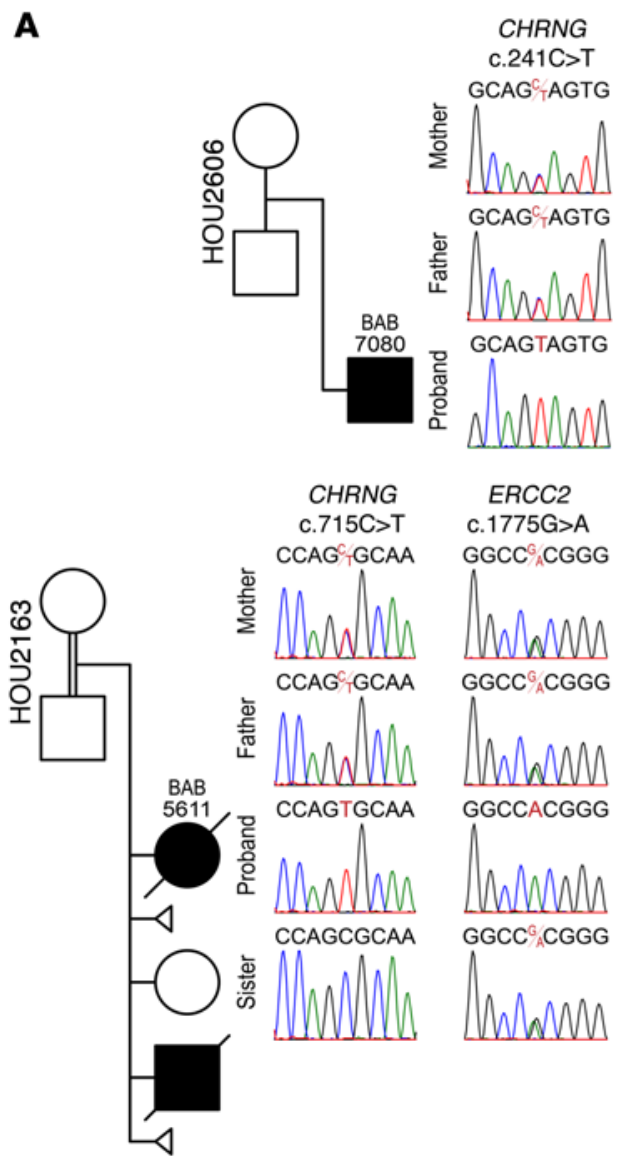

B

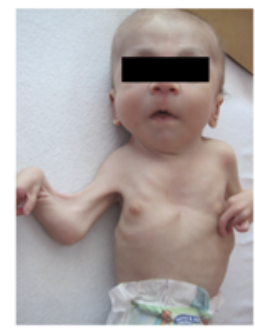

BAB7080

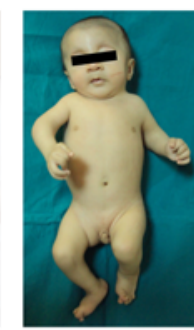

BAB4104

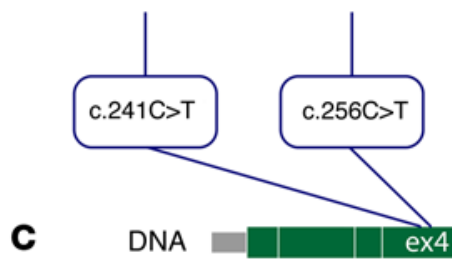

throw
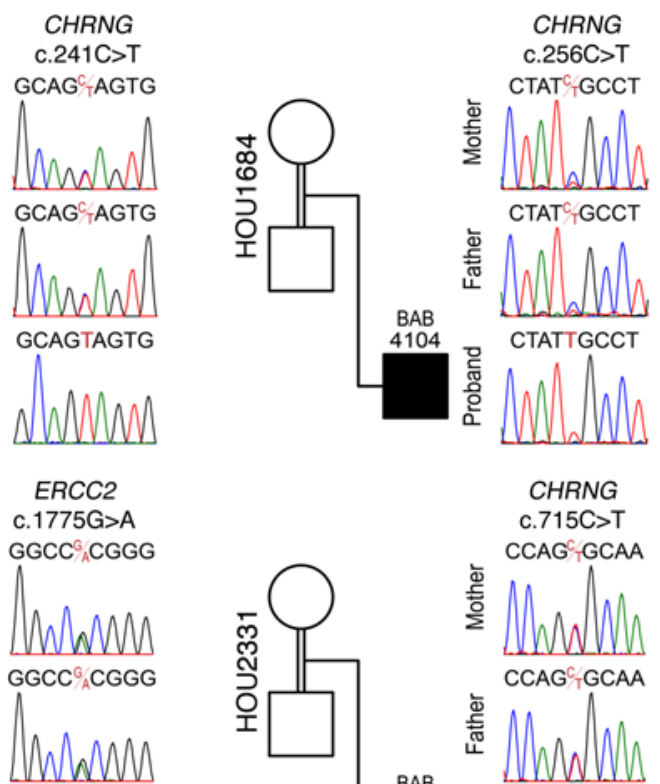

GGCCACGGG

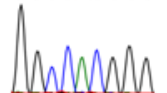

$\mathrm{GGCC}_{\wedge} \mathrm{CGGG}$

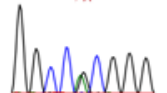

$\mathrm{GGCC}_{\mathrm{A}}^{\mathrm{C}} \mathrm{CGG}$

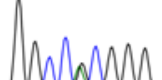

GGCC $^{\circ}$ CGGG

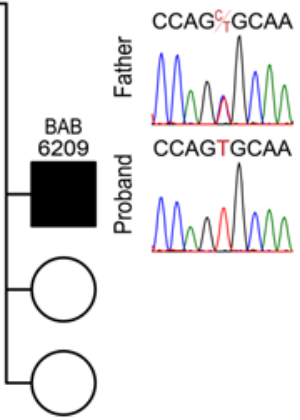

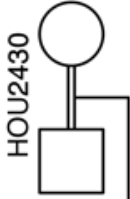

CHRNG

c.753_754 delCT

$\mathrm{CCCC}_{6} \mathrm{TGTG}$

产

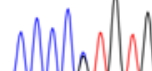

$\operatorname{CCCC}^{\mathrm{C}}{ }_{\mathrm{TGTG}}$
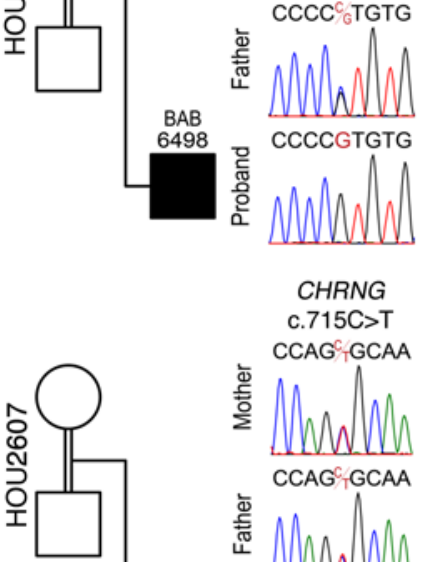

CCAG ${ }_{\top}^{\top} G C A A$

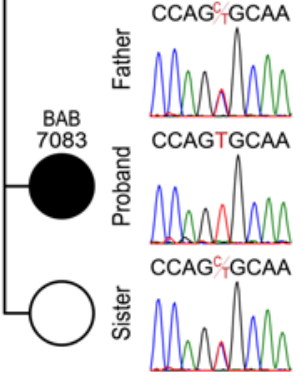

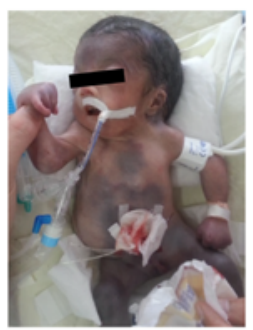

BAB6209

BAB5611
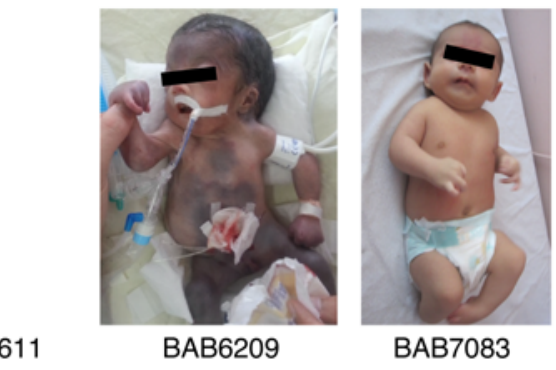

BAB7083

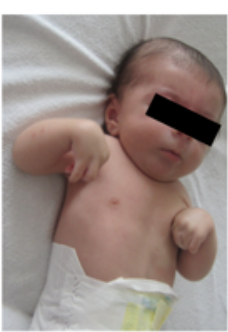

BAB6498

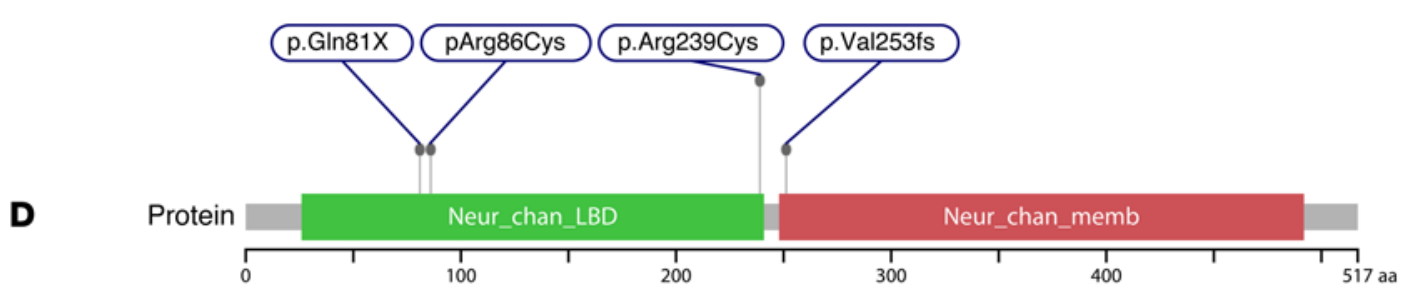

Figure 2. Segregation results, photographs, and variant distributions of the patients with CHRNG mutations. (A) Pedigrees and Sanger sequencing analyses of the patients that represent the proper segregation of the WES-detected CHRNG variants. One of the patients with more severe phenotype (BAB5611) has another homozygous variant in a known arthrogryposis gene (ERCC2), which also segregates in the family. (B) Photographs of the probands showing the major clinical features, including joint contractures, multiple pterygiums, and distinct facial dysmorphism. (C and D) Schematic representations of gene and protein structures of CHRNG and localization of the identified variants. Neur_chan_LBD, neurotransmitter-gated ion-channel ligand binding domain; Neur_chan_memb, neurotransmitter-gated ion-channel transmembrane region. 
Table 3. Patients with rare variants in a single novel candidate gene

\begin{tabular}{|c|c|c|c|c|c|c|c|c|c|c|}
\hline \multirow[t]{2}{*}{ Pedigree } & \multirow[t]{2}{*}{ Patient(s) } & \multirow[t]{2}{*}{ Clinical Findings } & \multirow[t]{2}{*}{ Gene } & \multirow[t]{2}{*}{ Variant } & \multirow[t]{2}{*}{ Zyg } & \multicolumn{5}{|c|}{ Count of the identified variant in other databases } \\
\hline & & & & & & Internal & TGP & ARIC & ESP & ExAC \\
\hline HOU2O61 & $\begin{array}{l}\text { BAB5239 } \\
\text { BAB5242 } \\
\text { BAB5246 }\end{array}$ & $\begin{array}{l}\text { APS: Webbing across the anterior aspect } \\
\text { of the cubital fossa and limitation of full } \\
\text { elbow extension }\end{array}$ & PSD3 & c.437T>c; p.lle146Thr & Het & 3 & 0 & 0 & 0 & 0 \\
\hline HOU2431 & BAB6499 & $\begin{array}{l}\text { DA with predominantly affection of the } \\
\text { fingers and feet, contractures of knees, } \\
\text { camptodactyly, and TEV }\end{array}$ & $\begin{array}{l}\text { MYO9A } \\
\text { MYO9A }\end{array}$ & $\begin{array}{l}\text { c.6845G>A; p.Gly2282Glu } \\
\text { c.608A>G; p.Tyr203Cys }\end{array}$ & $\begin{array}{l}\text { Het } \\
\text { Het }\end{array}$ & $\begin{array}{l}1 \\
3\end{array}$ & $\begin{array}{l}0 \\
0\end{array}$ & 1 & 0 & $\begin{array}{c}0 \\
27 / 121318 \text { het }\end{array}$ \\
\hline HOU2816 & BAB7826 & $\begin{array}{l}\text { Severe contractures of elbows and knees, } \\
\text { ulnar deviation of hands, TEV, and high- } \\
\text { arched palate }\end{array}$ & $\begin{array}{l}\text { FBN3 } \\
\text { FBN3 }\end{array}$ & $\begin{array}{l}\text { c.1883C>T; p.Ser628Phe } \\
\text { c.8357C>A; p.Cly2786Asp }\end{array}$ & Het & 3 & 0 & 0 & 0 & $\begin{array}{c}0 \\
2 / 116720 \text { het }\end{array}$ \\
\hline
\end{tabular}

Het, heterozygous; TEV, talipes equinovarus; TGP, 1,000 Genome Project; Zyg, zygosity.

affected sibling had nonlethal MPS $(15,20)$. Moreover, the same family had 4 additional cousins with nonlethal MPS phenotype and 1 deceased cousin. They concluded that, since the family represented a single observation, the significance of the clinical finding of variability of expression was unclear. We suggest that mutational burden or genetic load may contribute to clinical variability and disease severity, as has been shown in patients with CharcotMarie-Tooth disease, wherein genetic burden contributes to phenotypic variability and complex neuropathy (38).

Variants in both $M Y O 18 B$ and $M Y H 7 B$ that were identified in BAB7140 (Figure 3A) were recently reported in 2 separate studies in patients with common clinical findings of myopathy and vertebral anomalies. Alazami et al. identified a null homozygous mutation in MYO18B in 2 patients from 2 unrelated families that shared a similar phenotype of Klippel-Feil anomaly, myopathy, arthrogryposis, microcephaly, and distinctive facies (32). Esposito et al. identified 2 homozygous mutations in MYH7B and ITGA7 in a patient with congenital myopathy, scoliosis, and cardiomyopathy, and they concluded that a synergistic effect of these 2 mutations results in a severe phenotype (39). Our patient was a 14-year-old female and presented with more severe clinical findings, suggesting a blended phenotype (Figure 3B, Table 4, and ref. 40). The most remarkable finding in our patient was a high-grade thoracolumbar rotoscoliosis with cervical vertebral segmentation and fusion defects (Figure 3B). We compared the clinical features and identified mutations of our patient with those reported in 2 studies (Table 4). Our data strongly suggest that the mutational burden from the variants observed at the 2 genetic loci, $M Y O 18 B$ and $M Y H 7 B$, leads to a more severe and blended phenotype of arthrogryposis and vertebral anomalies, including high-grade scoliosis and fusion defects. Additionally, $\mathrm{AOH}$ findings based on data culled from WES showed that both $M Y O 18 B$ and $M Y H 7 B$ variants are surrounded by AOH blocks on chromosome 22 and 20, respectively. Interestingly, the $\mathrm{AOH}$ data detected on chromosome 20 revealed a large $\mathrm{AOH}$ block $(53.7 \mathrm{Mb})$ that nearly encompassed the entire chromosome ( $85 \%)$, suggesting a possible uniparental disomy (Figure $3 \mathrm{C}$ ), as has been recently reported with clinical exome sequencing for other recessive disease traits. Apart from the blended phenotype outcome of different homozygous vari- ants, the predicted structural similarity between these 2 myosin genes leads us to speculate that variants observed in these 2 genes in the same patient may induce a more severe disruption of the myosin gene network and cause a much more severe phenotype.

In family HOU2278, which had 2 affected siblings, we identified a homozygous frameshift mutation in COL6A3 in both patients. An additional homozygous missense mutation in BICD2 was also observed in the more severely affected elder brother, while the sister was a heterozygous carrier for this variant (Table 2). Mutations of both COL6A3 and BICD2 genes have previously been reported in muscle diseases comprising arthrogryposis $(41,42)$. However, while homozygous mutations of COL6A3 were reported in patients with Ullrich congenital muscular dystrophy (OMIM 254090), only heterozygous mutations of BICD2 were reported in patients with spinal muscular atrophy, lower extremity-predominant, type 2 (OMIM 615290). Our data suggest that the more severe phenotype observed in the brother might be a consequence of the mutational burden at the 2 loci and the biallelic homozygous inheritance of the BICD2 mutation.

In patient BAB6212, we identified a homozygous stop-gain mutation in GPR126, which was recently reported as a novel gene in 3 families with arthrogryposis (29). However, in this patient, WES data also revealed compound heterozygous variants in another novel gene, MYBPC2 (Figure 4A). MYBPC2 mutations were not previously associated with any Mendelian disease; however, mutations of $M Y B P C 1$, another myosin-binding protein, have previously been associated with DA type 1B (OMIM 614335) and lethal congenital contracture syndrome 4 (OMIM 614915) $(10,43)$. MYBPC proteins play structural and regulatory roles in muscle function. These proteins provide thick filament stability and modulate contractility through dynamic interactions with the head region of myosin and actin (44). Apart from these functional and molecular data, the mutated amino acids Thr236 and Ser255 are highly conserved in vertebrates (Figure 4B), and MYBPC2 has close interactions with various known arthrogryposis genes (Figure 4C). Although GPR126 mutations were recently associated with arthrogryposis, MYBPC2 may also be considered as a contributory gene to the patient's phenotype due to the gene function and interactome structure of its protein product. 
A

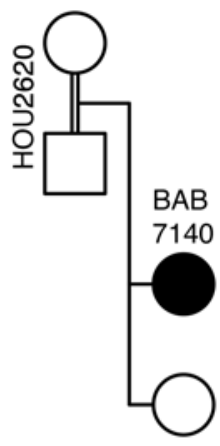

MYO18B c. $6322 \mathrm{C}>\mathrm{T}$ CGGC,GAAA

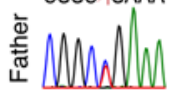

CGGCTGAAA

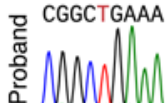
CGGCCGAAA

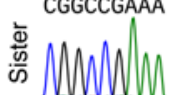

MYH7B C.3950G $>\mathrm{A}$ $\mathrm{CAGC}_{A} \mathrm{GCAG}$

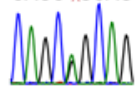

CAGCAGCAG

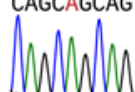

CAGC ${ }_{A}$ GCAG
B

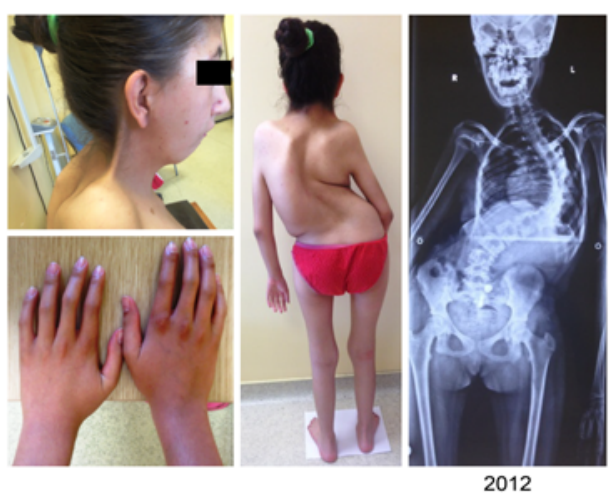

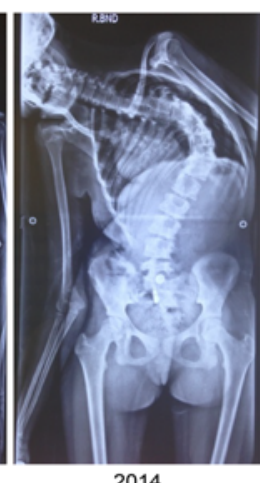

2014
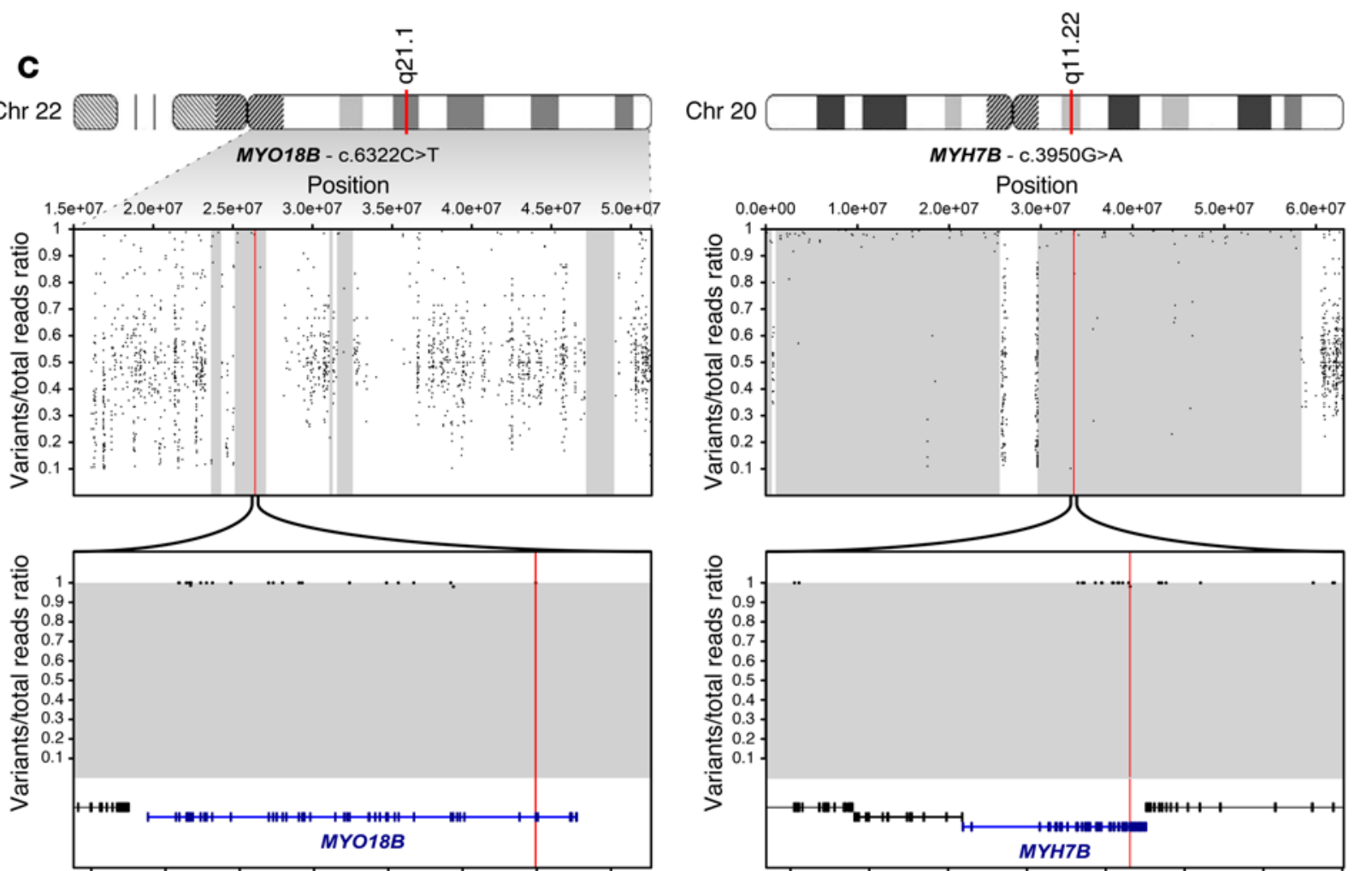

2610000026150000262000002625000026300000263500002640000026450000 Position

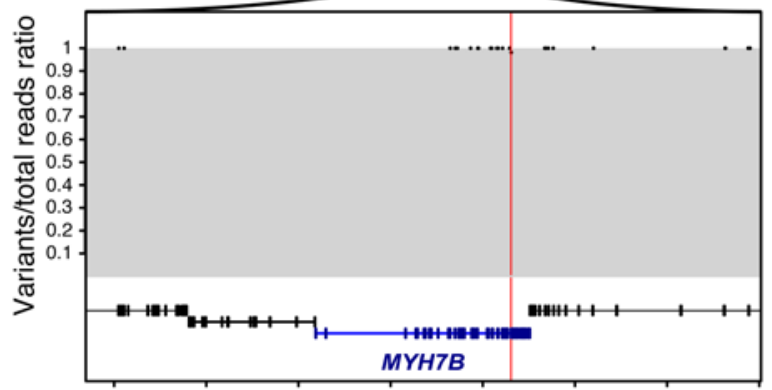

$33500000 \quad 33520000 \quad 33540000 \quad 33560000 \quad 33580000 \quad 33600000 \quad 33620000 \quad 33640000$

Position

Figure 3. MYO18B and MYH7B variants identified in patient BAB7140. (A) The pedigree of the HOU2620 family and segregation of the MYO18B and MYH7B variants. DNA sample of the mother was not available. (B) Patient photographs and X-ray images showing the severe phenotype most probably due to the synergistic effect of 2 homozygous mutations in 2 different arthrogryposis-related genes. Note the progressive scoliosis observed in the $X$-rays taken in 2012 and 2014, respectively. (C) Top panel: B-allele frequency plot of the entire chromosome 22 and 20, respectively. Bottom panel: Zoomed-in views of the regions encompassing MYO18B and MYH7B indicated by blue. $\mathrm{AOH}$ regions are shown as gray regions. Note the large $\mathrm{AOH}$ block that nearly encompass entire chromosome 20 , suggesting a possible uniparental disomy.

In 2 patients (BAB7302 and BAB7125), we identified different homozygous stop-gain mutations in LIFR, consistent with StuveWiedemann syndrome (SWS) (OMIM 601559) (45). In both cases, we also identified potential contributory variants in other known genes (Table 2). Patient BAB7302 had compound heterozygous mutations in $P I 4 K A$, a gene recently associated with brain malformation and arthrogryposis (33). Patient BAB7125 had compound heterozygous variants in MYH14 (Table 2), which encodes a member of the nonmuscle myosin II family of ATP-dependent molecular motors that interact with cytoskeletal actin and regulate cytokinesis, cell motility, and cell polarity (46). Heterozygous mutations of MYH14 were reported in a family with a complex phenotype of peripheral neuropathy, myopathy, hoarseness, and hearing loss (47). Our patient was a 15-month-old male and had severe developmental delay, multiple joint contractures, pectus excavatum, scoliosis, hypertrophy in calf muscles, and mild mitral valve insufficiency. Although our patient had a normal hearing test and creatine kinase level, the neurologic findings and calf enlargement, which is a typical clinical feature in neuromuscular diseases, suggest that the compound heterozygous mutations of MYH14, in addition to LIFR homozygous mutation, may contribute to the severe phenotype observed in our patient due to a potential mutational burden effect. 
Table 4. Comparison of the genotype and clinical findings in patient BAB7140 harboring MYO18B and MYH7B mutations with those of recently reported patients that represent similar findings

\begin{tabular}{|c|c|c|c|c|c|c|}
\hline \multirow{3}{*}{$\begin{array}{l}\text { Genotype } \\
\text { Identified gene(s) }\end{array}$} & \multicolumn{2}{|c|}{ Alazami et al. (ref. 32) } & \multirow{2}{*}{\multicolumn{2}{|c|}{$\begin{array}{c}\text { Esposito et al. (ref. 39) } \\
\text { Patient } 3\end{array}$}} & \multirow{2}{*}{\multicolumn{2}{|c|}{$\begin{array}{l}\text { Present study } \\
\text { BAB7140 }\end{array}$}} \\
\hline & \multirow{2}{*}{$\begin{array}{l}\text { Patient } 1 \\
\text { MY018B }\end{array}$} & \multirow{2}{*}{$\begin{array}{c}\text { Patient } 2 \\
\text { MY018B }\end{array}$} & & & & \\
\hline & & & MYH7B & ITGA7 & MY018B & MYH7B \\
\hline Identified variant(s) & p.Ser2302X & p.Ser2302X & p.Arg890Cys & p.Glu882Lys & p.Arg2108X & p.Arg1317GIn \\
\hline Variant type & Nonsense & Nonsense & Missense & Missense & Nonsense & Missense \\
\hline Zygosity & Homozygous & Homozygous & Homozygous & Homozygous & Homozygous & Homozygous \\
\hline \multicolumn{7}{|l|}{ Clinical history } \\
\hline Ethnic origin & Arab & Arab & \multicolumn{2}{|c|}{ Italian } & \multicolumn{2}{|c|}{ Turkish } \\
\hline Consanguinity & Yes & Yes & \multicolumn{2}{|c|}{ Yes } & \multicolumn{2}{|c|}{ Yes } \\
\hline Sex & Male & Female & \multicolumn{2}{|c|}{ Female } & \multicolumn{2}{|c|}{ Female } \\
\hline Premature delivery & Yes & No & \multicolumn{2}{|c|}{$\mathrm{N} / \mathrm{A}$} & \multicolumn{2}{|c|}{ Yes } \\
\hline Delayed motor development & Yes & Yes & \multicolumn{2}{|c|}{ Yes } & \multicolumn{2}{|c|}{ Yes } \\
\hline Hypotonia & Yes & Yes & \multicolumn{2}{|c|}{ Yes } & \multicolumn{2}{|c|}{ Yes } \\
\hline Short stature & Yes & Yes & \multicolumn{2}{|c|}{$\mathrm{N} / \mathrm{A}$} & \multicolumn{2}{|c|}{ Yes } \\
\hline Microcephaly & Yes & Yes & \multicolumn{2}{|c|}{$\mathrm{N} / \mathrm{A}$} & \multicolumn{2}{|c|}{ No } \\
\hline Ptosis & Yes & Yes & \multicolumn{2}{|c|}{ No } & \multicolumn{2}{|c|}{ Yes } \\
\hline Arched eyebrows & Yes & Yes & \multicolumn{2}{|c|}{ No } & \multicolumn{2}{|c|}{ Yes } \\
\hline Hypertelorism & Yes & Yes & \multicolumn{2}{|c|}{ No } & \multicolumn{2}{|c|}{ Yes } \\
\hline Bulbous nose & Yes & Yes & \multicolumn{2}{|c|}{ No } & & \\
\hline Low-set ears & No & Yes & & & & \\
\hline Micrognathia & No & Yes & & & & \\
\hline Low posterior hair line & Yes & Yes & & & & \\
\hline Webbed neck & No & Yes & & & & \\
\hline Arthrogryposis & Yes & No & & & & \\
\hline Vertebral fusion defect & Yes & Yes & & & & \\
\hline Scoliosis & No & Yes & & & Yes & ade) \\
\hline Hip deformity & No & Yes & & & & \\
\hline Creatine kinase & Normal & Normal & & & & \\
\hline Electromyography & Myopathy & N/A & & & & \\
\hline Muscle biopsy & Pathologic & N/A & & & & \\
\hline Echocardiography & N/A & $\mathrm{N} / \mathrm{A}$ & Carc & athy & & \\
\hline
\end{tabular}

In patient BAB7143, a homozygous missense variant in a novel gene, VPS8, was identified (Figure 5A). The patient had multiple joint contractures, delayed motor milestones, craniofacial dysmorphism, and cerebellar vermis hypoplasia detected in cranial magnetic resonance imaging (MRI) (Figure 5B and Table 2). VPS8 is one of the Vps proteins that functions in endosomal biogenesis and Golgi-to-lysosome trafficking in yeast $(48,49)$. Homozygous or compound heterozygous mutations in other Vps genes, VPS33B and VPS53, were previously associated with arthrogryposis-renal dysfunction-cholestasis syndrome (ARCS) type 1 (OMIM 208085) and pontocerebellar hypoplasia type 2E (PCH2E) (OMIM 615851), respectively $(50,51)$. Joint contractures and cerebellar anomalies were previously defined in patients with PCH2E (52). Moreover, VPS8 has close interactions with VPS33B and VPS53, as well as VIPAS39 (Figure 5C), and mutations of VIPAS39 were associated with ARCS type 2 (OMIM 613404) (53). Thus, VPS8 is a potential candidate gene for the arthrogryposis and MRI findings observed in our patient. Since the observed brain anomalies in the subject are not common findings in disorders with arthrogryposis, we further examined the exome data for an additional variant that may explain the MRI findings, and we identified another homozygous missense variant in POLR3A. POLR3A is not a known gene for arthrogryposis, but homozygous mutations in POLR3A have been associated with hypomyelinating leukodystrophy-7 (HLD7) (OMIM 607694) (54). HLD7 is an autosomal recessive neurodegenerative disorder characterized by childhood onset of progressive motor decline manifest as spasticity, ataxia, tremor, cortical and cerebellar atrophy, as well as mild cognitive regression. The cerebellar component of HLD7 suggests that the identified POLR3A variant may have a role in the intracranial findings in this patient. The missense changes in VPS8 and POLR3A both affect highly conserved valine residues on the respective proteins (Figure 5D).

In another patient (BAB7713) with arthrogryposis and cardiomyopathy findings, we identified homozygous mutations in 2 different known genes, RIPK4 and LMNA. The major clinical features of the subject were contractures of hands and feet, myopathy, hypotonia, and dilated cardiomyopathy detected by echocardiogram. RIPK4 is a known gene for popliteal pterygium syndrome type 2 (OMIM 263650), and LMNA mutations were reported in several allelic disorders, including dilated cardiomyo- 
A
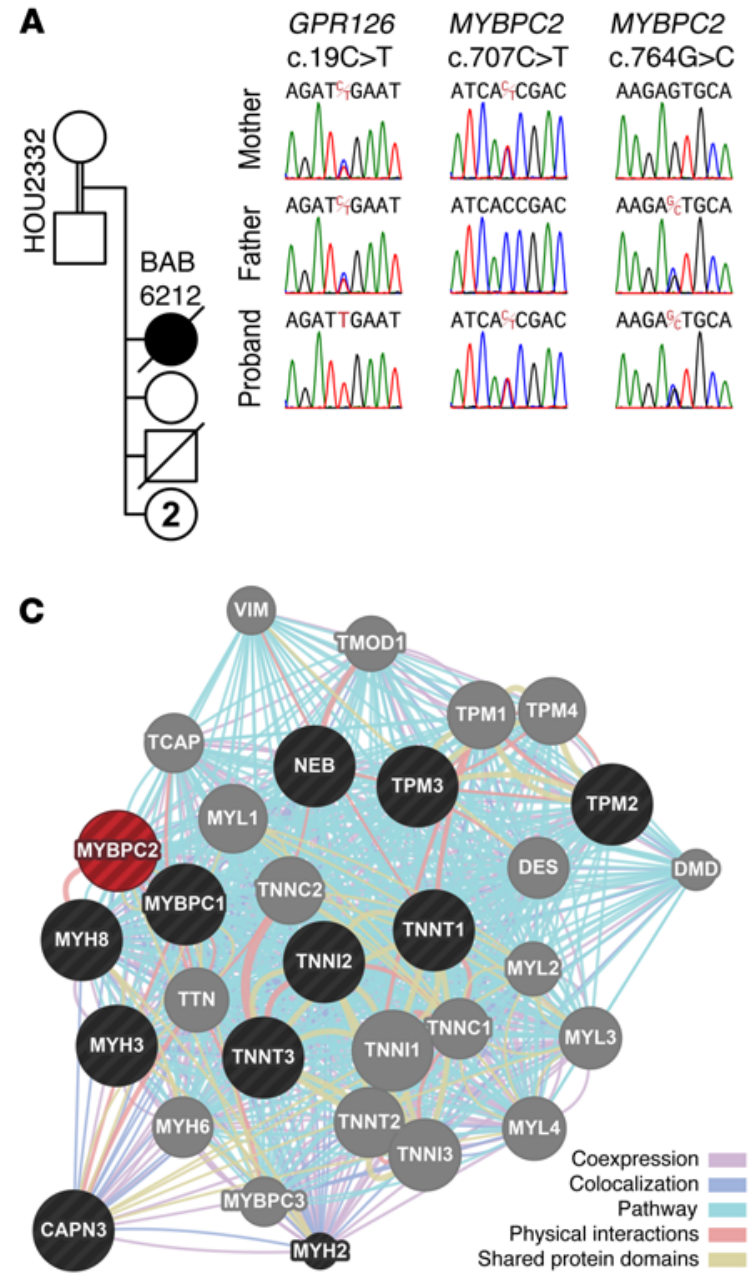

MYBPC2 MYBPC2

ATCA ICGAC AAGAGTGCA

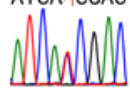

ATCACCGAC

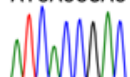

ATCA CGAC

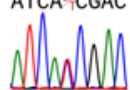

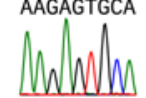

AAGA ${ }^{G}$ TGCA

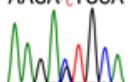

AAGA $^{\circ}$ TGCA

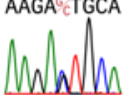

B $\quad$ MYBPC2 MYBPC2

p.Thr236lle p.Ser255Thr

$\downarrow \downarrow \downarrow$

Human YGITDLR VKKSAAG

Rhesus YGITDLR VKKSAAG

Mouse YGITDLR VKKSAAG

Dog YGITDLR VKKSAAG

Elephant YGITDLR VKKSAAG

Frog YGITDLR EKKSEAG

Zebrafish YGITDLR PKKSDAG

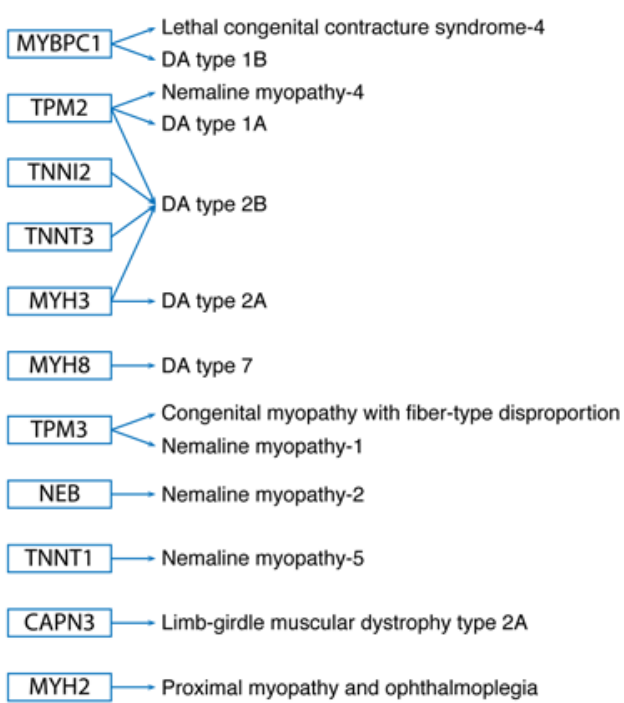

Figure 4. Variants in GPR126 and $M Y B P C 2$ identified in patient BAB6212. (A) Segregation analyses of the homozygous GPR126 and compound heterozygous MYBPC2 mutations in the family HOU2332. (B) Conservation alignment indicating that the affected amino acids of MYBPC2 are conserved across different vertebrates. (C) The interaction network of MYBPC2 (red circle) with known arthrogryposis gene products (black circles). Gray circles indicate the proteins in the same network but not associated with arthrogryposis previously. pathy type 1A (OMIM 115200). The homozygous variant detected in RIPK4 is a novel variant, but the LMNA variant has previously been reported in a patient with interstitial myocardial fibrosis (55). The identified rare homozygous variants in this subject and previously associated disorders suggest that RIPK4 mutation is responsible for the observed joint contractures while the LMNA mutation may cause cardiac features and myopathy.

Patients that represent phenotypic expansion. In 3 patients, we identified novel homozygous variants in known genes; however, the clinical findings we observe in association with the newly described variant alleles suggest phenotypic expansion for trait manifestations previously attributed to this gene. In patient BAB3931, we identified a novel homozygous missense mutation in CENPJ, the causal gene for Seckel syndrome (SCKL) type 4 (OMIM 613676) and autosomal recessive microcephaly type 6 (MCPH-6) (OMIM 608393). Arthrogryposis is not a typical finding of SCKL type 4, but elbow-flexion contracture, hip dislocation, and talipes deformities were defined in SCKL type 1 (OMIM 210600). Moreover, Sarici et al. reported a Turkish patient with SCKL, accompanied by semilobar holoprosencephaly and arthrogryposis (56). The clinical findings of our patient overlapping with SCKL and the previously reported Turkish patient include microretrognathia, high-arched palate, crowded and decayed teeth, low-set ears, elbow-flexion contracture, ulnar deviation of hands, talipes equinovarus, and delayed bone age measured via hand X-ray (Supplemental Figure 3). Besides these, our patient was not microcephalic, and his growth parameters were in the normal range when measured at 6 years of age, unlike typical SCKL patients. Additionally, another remarkable finding of our patient was abnormal scar formation with wound healing observed on his left foot (Supplemental Figure 3), which suggests possible connective-tissue involvement in his phenotype. Further analysis of the exome data did not reveal a reasonably plausible variant that might explain the abnormal scar formation in the patient. Clinical features of our patient overlapping with SCKL and distinct findings including arthrogryposis and abnormal wound healing suggest that the homozygous mutation of CENPJ observed in our patient may cause another allelic disorder apart from SCKL type 4 and MCPH- 6 or may represent phenotypic expansion of CENPJ-related diseases.

In one male patient (BAB3955), we identified a hemizygous variant in IDS, which is a known gene for mucopolysaccharidosis type 2 (MPS2) (OMIM 309900). MPS2 is an X-linked metabolic disorder caused by deficiency of the lysosomal enzyme iduronate sulfatase that leads to progressive accumulation of glycosaminoglucans in nearly all cell types. The typical clinical features include severe airway obstruction; skeletal deformities, including joint contractures; cardiomyopathy; and neurologic decline (57). The 
A

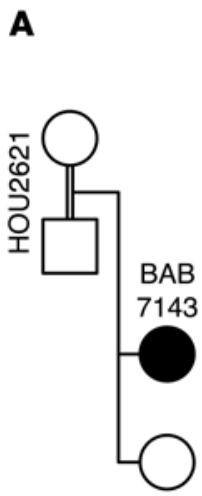

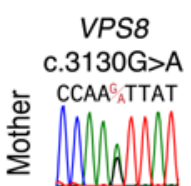

- CCAA ${ }^{\text {ATTAT }}$
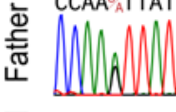

믈 CCAAATTAT

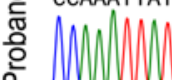

POLR3A

c. $3388 \mathrm{G}>\mathrm{A}$

TCTC $_{A}$ TCAA

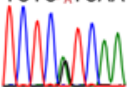

TCTC $_{\text {ATCAA }}$

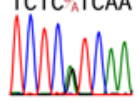

TCTCATCAA

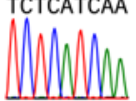

B

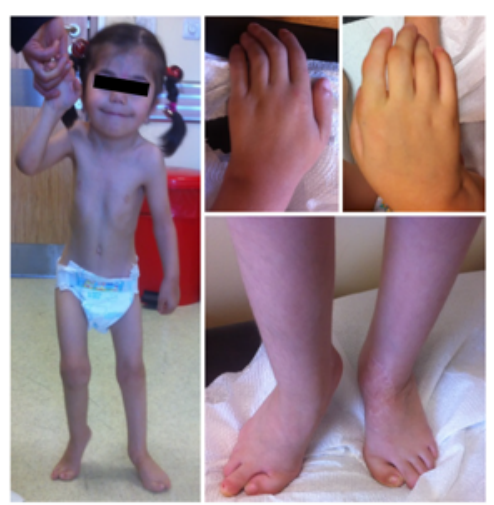

D

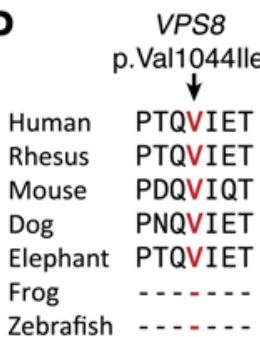

POLR3A

p.Val1130lle $\downarrow$

SLKVLIF

SLKVLIF

SLKVLIF

SLKVLIF

SLKVLIF

SLKVLIF

SLKVLLF

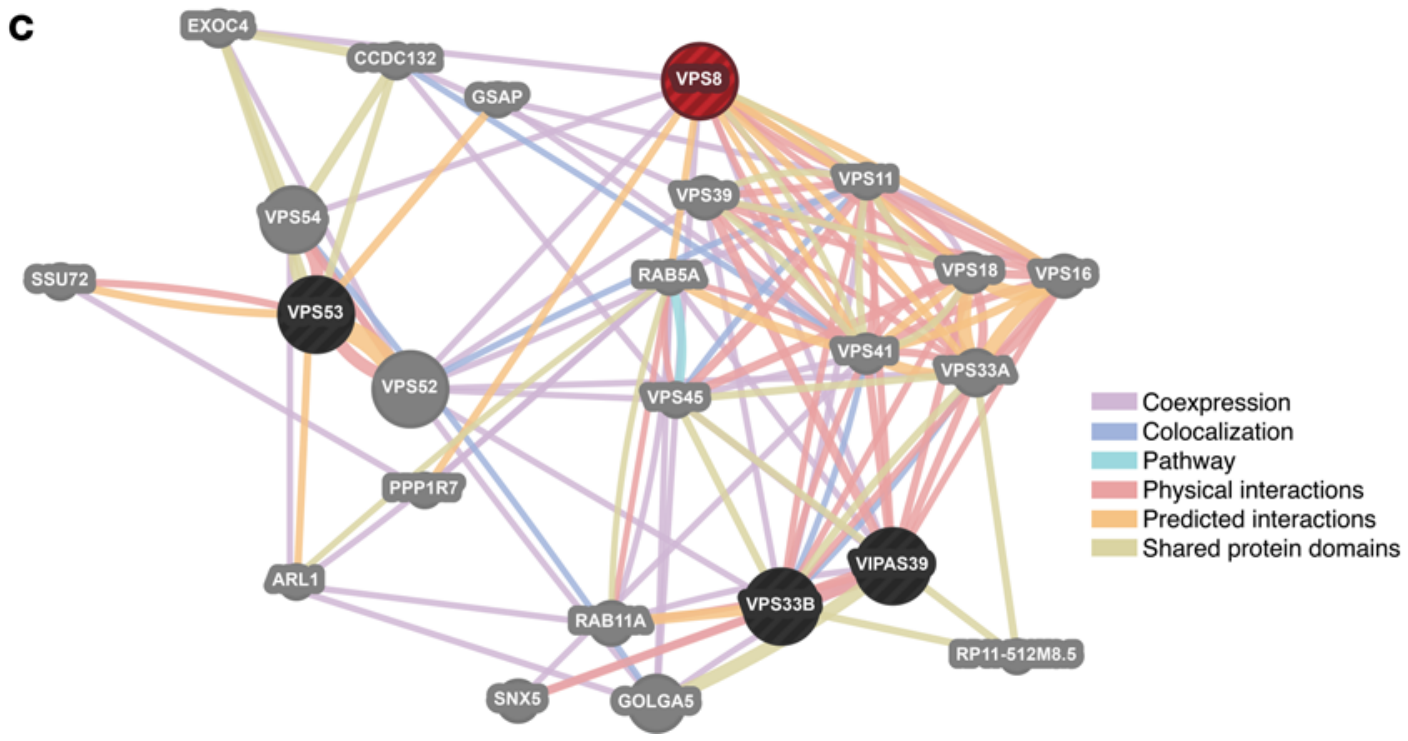

Figure 5. Homozygous VPS8 and POLR3A variants identified in BAB7143. (A) Segregation analyses of the WES-detected variants. The proband was homozygous, and the parents were heterozygous carrier, consistent with Mendelian expectations. (B) Patient photographs showing clinical features, including ptosis, joint contractures, ulnar deviation of the hands, and surgically repaired foot deformity. (C) The interaction network of VPS8 (red circle) with other gene products, such as VPS33B, VPS53, and VIPAS39 (black circles), which were previously associated with different arthrogryposis-related disorders. Gray circles indicate the proteins in the same network but not associated with arthrogryposis previously. (D) Peptide alignment showing the conservation of the affected amino acids across the species.

overlapping findings of our patient with MPS2 were delayed neuromotor development, growth retardation, seizures, laryngomalacia, flexion contractures of hands, and hepatosteatosis. However, our patient did not present with some other typical clinical manifestations of MPS2, such as coarse facies and macrocephaly, and he was clinically diagnosed with spinal muscular atrophy due to decreased intrauterine fetal movements and anterior horn cell involvement of spinal cord detected in EMG. Therefore, the enzymatic analysis to confirm MPS2 was not performed during the patient followup. Because the patient died at 1.5 years of age, we suggest that clinical evidence for MPS2 may not have yet developed or that the identified mutation may have resulted in phenotypic expansion in the patient.

We identified a homozygous novel variant in GBE1 in patient BAB3960. The mutations in GBE1 were previously associated with glycogen storage disease type 4 (GSD4) (OMIM 232500). Glycogen branching enzyme deficiency is causative of GSD4 that is characterized by the accumulation of polyglucosan in almost all tissues. Clinical features of the typical GSD4 are failure to thrive, hepatosplenomegaly, and liver cirrhosis leading to death in early childhood (58). However, GSD4 can show extreme clinical heterogeneity, and different clinical manifestations may present, such as nonprogressive hepatic form and neuromuscular forms. Arthrogryposis is one of the characteristic findings of the congenital neuromuscular form of GSD4, which is mostly seen with hydrops fetalis and perinatal death. There are also juvenile and adult neuromuscular forms that are dominated by myopathy, and the classic clinical manifestation of liver cirrhosis generally is not present in these neuromuscular forms (59-61). The diagnosis of GSD4 can be confirmed by the determination of the branching enzyme activity in affected tissues. However, the commonly used assays are indirect and not sensitive enough for accurate evaluation of low levels of branching activity $(60,62)$. In our 2-year-old male patient, the presence of joint contractures was compatible with the congenital neuromuscular form, but the clinical manifestation was not severe. Additional patient findings suggesting phenotypic expansion were cleft palate, pterygium colli, pelvicaliectasis, cryptorchidism, and tall vertebral bodies detected on X-ray, which, to 
A

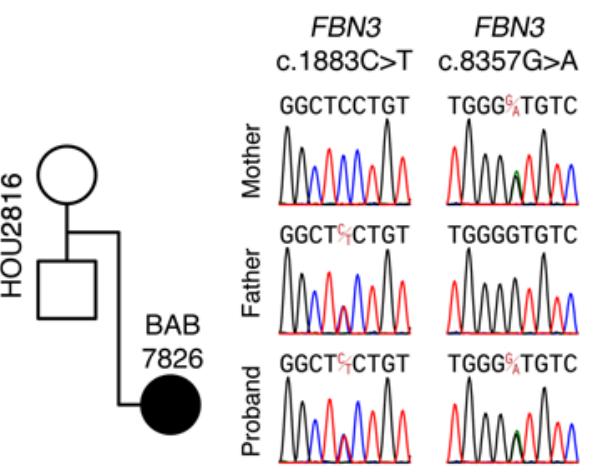

B

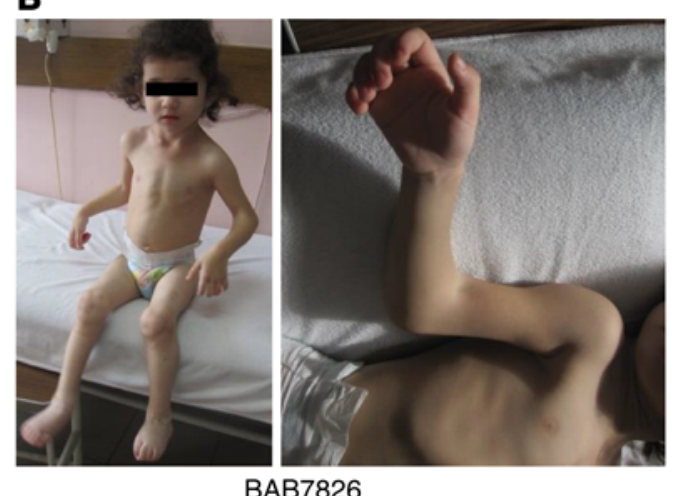

BAB7826

Figure 6. Variants in FBN3 identified in BAB7826. (A) Family pedigree and segregation results of the identified compound heterozygous variants in FBN3. (B) Patient photographs showing the representative clinical sign of arthrogryposis.

the best of our knowledge, were not reported in GSD4 patients previously. Also, the general hypotonia detected in the subject was compatible with the juvenile form. We suggest that our data support the clinical heterogeneity of GSD4 and expand the phenotypic spectrum with the novel clinical findings.

Patients with rare deleterious variants in a single novel candidate gene. We identified compound heterozygous variants in FBN3 in patient BAB7826 (Figure 6A). The subject had multiple joint contractures with severely affected elbows and knees (Figure 6B). $F B N 3$ is one of the fibrillin genes that function in the structural architecture of connective tissues; mutations of FBN3 have not been reported in any Mendelian disorder. Other fibrillin genes, $F B N 1$ and $F B N 2$, were previously associated with disorders comprising arthrogryposis, but $F B N 3$ was not. Mutations of $F B N 1$ were described in autosomal dominant Weill-Marchesani syndrome (OMIM 277600), and FBN2 mutations are associated with DA type 9, also known as Beals syndrome (OMIM 121050). Our data lead us to speculate that mutations of $F B N 3$ may also cause arthrogryposis, as found for other fibrillin gene mutations.

The exome analysis of BAB6499 revealed 2 heterozygous variants in MYO9A, one of which is de novo and the other inherited from the mother (Figure 7A). The subject had DA with predominant involvement of the fingers and feet (Figure 7B). Mutations of $M Y O 9 A$ were not previously associated with any human disease. MYO9A is one of the unconventional myosins that are members of the myosin superfamily that display the general domains of conventional myosins $(63,64)$. In a mouse study, Northern blot analysis detected mouse Myo9a expression in limb buds, and in situ hybridization to limb buds suggested that Myo9a may be localized to the precartilagenous mesenchyme (65). Also in the same study, Myo9a was shown to be expressed in the skeletal and the nervous systems, 2 important systems where dysfunction may play a role in the formation of arthrogryposis and consistent with the hypothesis that mutations of MYO9A may cause arthrogryposis. Moreover, the mutated amino acids Gly2282 and Tyr203 are highly conserved in vertebrates (Figure 7C), and MYO9A has interactions with some other myosins that have previously been associated with arthrogryposis disorders (Figure 7D). The segregation pattern of identified variants in our patient suggests that deleterious de novo mutations or compound heterozygous mutations of MYO9A may cause arthrogryposis.

In family HOU2061 with 8 affected individuals diagnosed with APS, we applied WES to 3 affected cousins, and a heterozygous variant in PSD3 was detected and shown to cosegregate with autosomal dominant arthrogryposis. To confirm this identified variant, we analyzed 12 individuals from 4 generations in the pedigree with available DNA (8 affected, 4 unaffected) by Sanger sequencing. We observed that all affected individuals were carriers for the same mutation, while the unaffected kindred were normal for the same allele (Figure 8A). Additionally, we calculated the logarithm of odds (LOD) score, and we found that, based on the family size, our data $(\theta=0$, LOD score $=1.806)$ supports the potential linkage of PSD3 to the phenotype. The function of PSD3 is not well established, and mutations of PSD3 were not reported in any Mendelian disorder; however, the association of PSD 3 with systemic sclerosis - which is a heterogeneous disorder characterized by extensive skin fibrosis, microvascular changes, and autoimmunity - was reported (66). The skin fibrosis component of systemic sclerosis might be a clue for explaining the phenotype observed in APS patients with PSD3 mutation by reason of the fact that the main phenotype observed in APS is skin webbing around the elbow joint (Figure 8B). Nevertheless, the biological mechanism underlying APS and molecular pathway of PSD3 needs to be investigated further.

In summary, beside the known and novel variants in known genes, we identified variants in 5 potential novel candidate genes (FBN3, MYBPC2, MYO9A, PSD3, and VPS8) in patients with different arthrogryposis subtypes. Three of 5 novel genes were observed as a single causal gene, while variants in 2 novel candidate genes were identified as a second locus in addition to a known gene that may affect the phenotype with a mutational load or may cause a blended phenotype. Moreover, we identified a potential mutational burden in 6 patients with homozygous or compound heterozygous mutations in 2 different known genes. In 4 of 6 patients, both identified genes were previously associated with an arthrogryposis disorder, and the mutational burden may have contributed to the clinical severity observed (38); meanwhile, in 2 of 6 patients, the identified genes - in addition to known arthrogryposis genes - were associated with different disorders without arthrogryposis and resulted in an apparent blended phenotype with clinical manifestations of both disorders (40,67). Arthrogryposis is observed in a broad group of genetically heterogeneous disorders with unknown molecular etiology in the considerable majority. In our study, the WES method enabled us to investigate potential oligogenic or mutational burden models, as well as to 
A

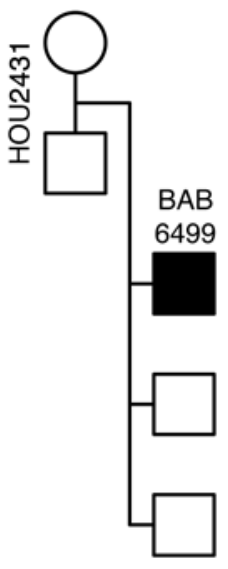

C

$\begin{array}{ll}\text { Human } & \text { RIRGKG } \\ \text { Rhesus } & \text { RIRGKG } \\ \text { Mouse } & \text { HIRGKG } \\ \text { Dog } & \text { RLRGKG } \\ \text { Elephant } & \text { RIRGKG } \\ \text { Chicken } & \text { RVRGKG } \\ \text { Frog } & \text { RLRGKG } \\ \text { Zebrafish } & \text { HVPGKG }\end{array}$

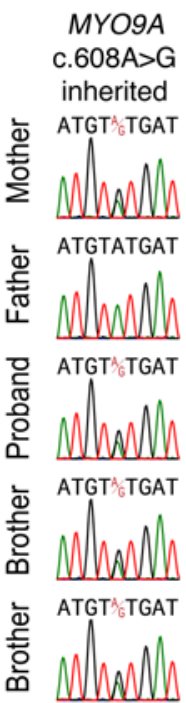

MYO9A

p.Tyr203Cys

$\downarrow$

HNDYMKV

HNDYMKV

HNDYMKV

HNDYMKV

HNDYMKV

HNDYMKV

RNDYMKV

HNDYMKV

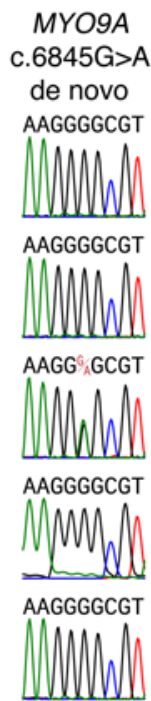

B
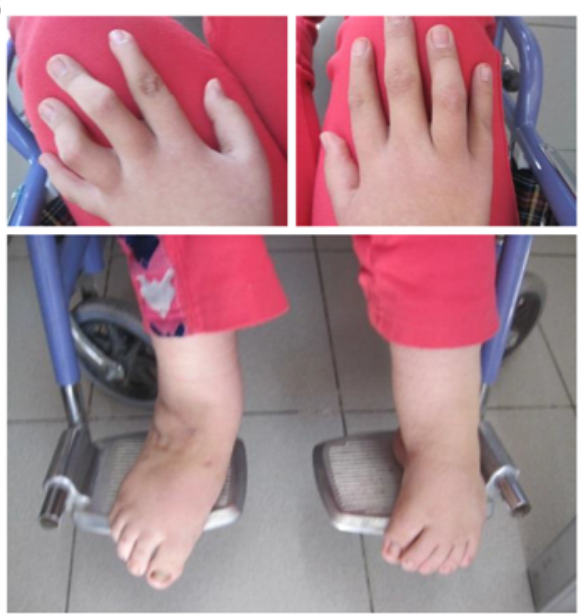

D

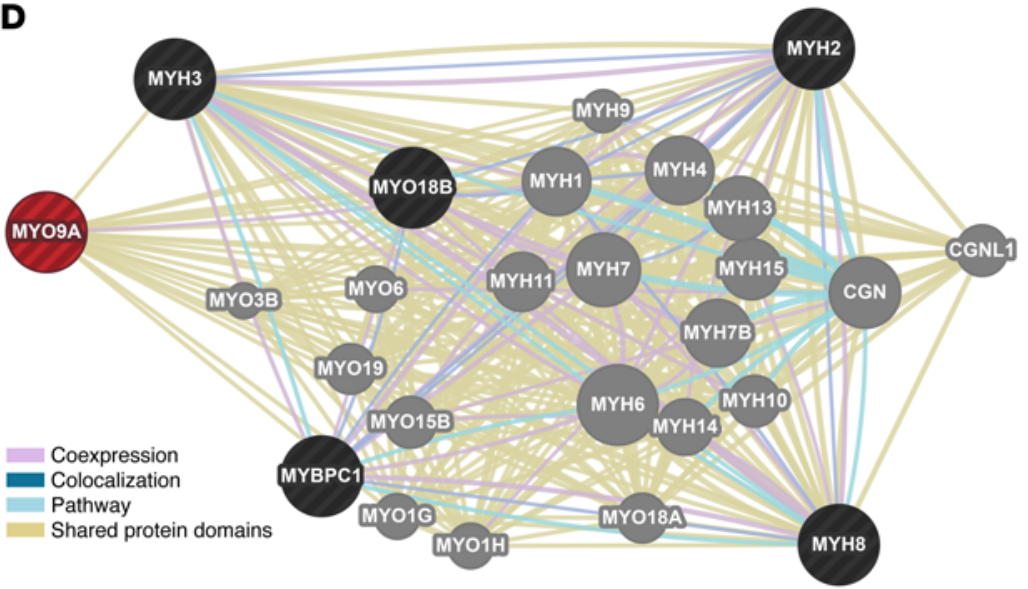

Figure 7. MYO9A variants identified in BAB6499. (A and B) Segregation analyses of the identified MYO9A variants and patient photographs. While c.608A $>$ G variant is inherited from the mother, c.6845C >A variant is observed as de novo. (C) Peptide alignment of human MY09A with MY09A in other species. Gly2282 and Tyr203 are conserved residues across all vertebrates. (D) Interactome of MYO9A (red circle) that shows the interactions with known arthrogryposis gene products (black circles). Gray circles indicate the proteins in the same network but not associated with arthrogryposis previously.

identify novel candidate genes in arthrogryposis patients. We suggest that using genomic sequencing methods in patient populations with arthrogryposis disorders may identify novel arthrogryposis genes and provide further molecular etiological insights into this phenotype, as well as provide opportunities to uncover novel genetic mechanisms, including potential contributions of multilocus variation.

\section{Methods}

Human subjects and sample collection. Fifty-one Turkish patients and 1 Arab patient with arthrogryposis were evaluated by 1 or more pediatricians and/or clinical geneticists. Genomic DNA was extracted from whole blood using the Gentra Puregene Blood Extraction Kit per the manufacturer's protocol (QIAGEN). All the genomic studies were performed on the DNA samples extracted from whole blood.

WES and data analysis. Samples from all patients underwent WES at Baylor College of Medicine Human Genome Sequencing Center through the Baylor-Hopkins Center for Mendelian Genomics research initiative. Genomic DNA samples obtained from patients processed according to protocols previously described (68). Briefly, DNA sample was prepared into Illumina paired-end libraries and underwent whole-exome capture using BCM-HGSC core design (52 Mb, NimbleGen, Roche Sequencing), followed by sequencing on the Illumina HiSeq 2000 platform with an approximately $150 \times$ depth of coverage. Data produced was aligned and mapped to the human genome reference sequence (hg19) using the Mercury pipeline. Variants were called using the ATLAS (an integrative variant analysis pipeline optimized for variant discovery) variant calling method and SAMtools (The Sequence Alignment/Map) and annotated using the in-house-developed Cassandra annotation pipeline that uses ANNOVAR (http:// annovar.openbioinformatics.org/en/latest/) (69-71).

The findings of WES studies were deposited into the NCBI's database of Genotypes and Phenotypes (dbGaP) archive (phs000711. v3.p1) (http://www.ncbi.nlm.nih.gov/gap/).

$P C R$ validation and segregation analyses. To confirm the identified WES-detected variant, we applied Sanger sequencing following PCR amplification, and segregation analyses were performed on all DNA-available members of the families. Same pairs of primers are 
A
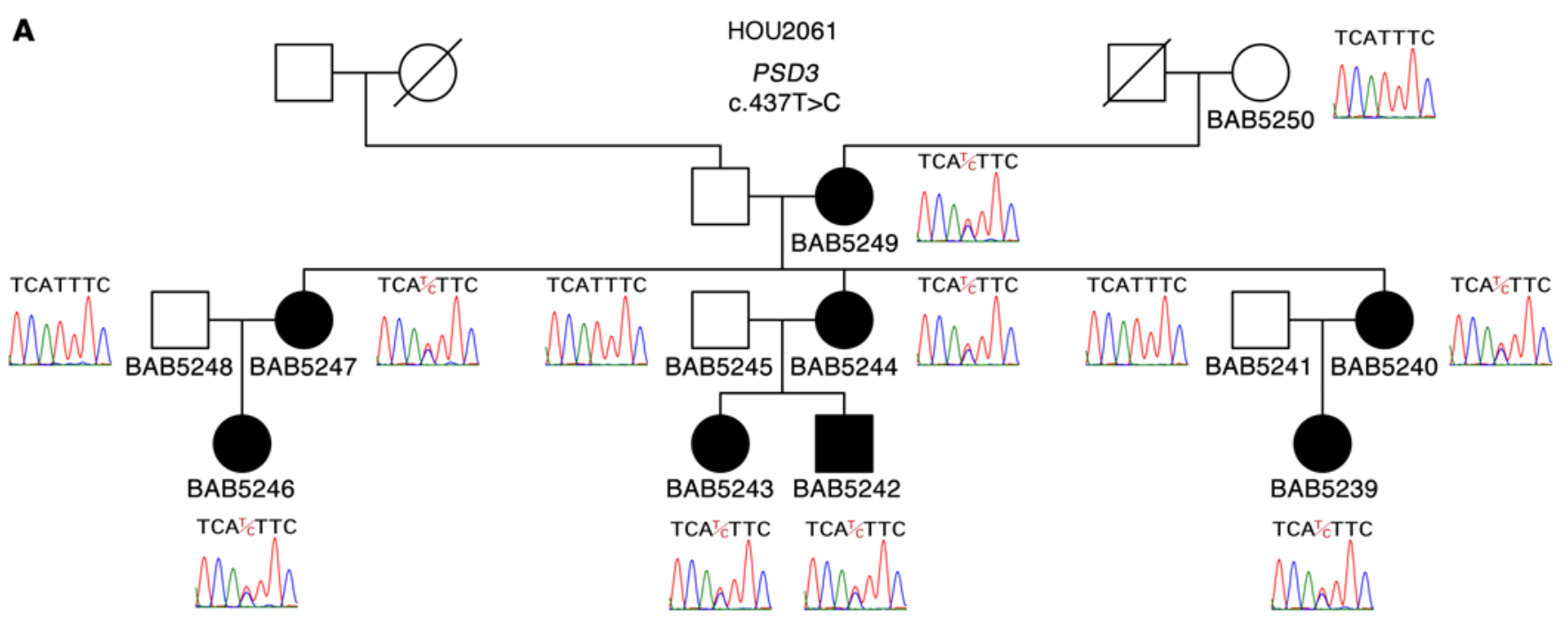

B
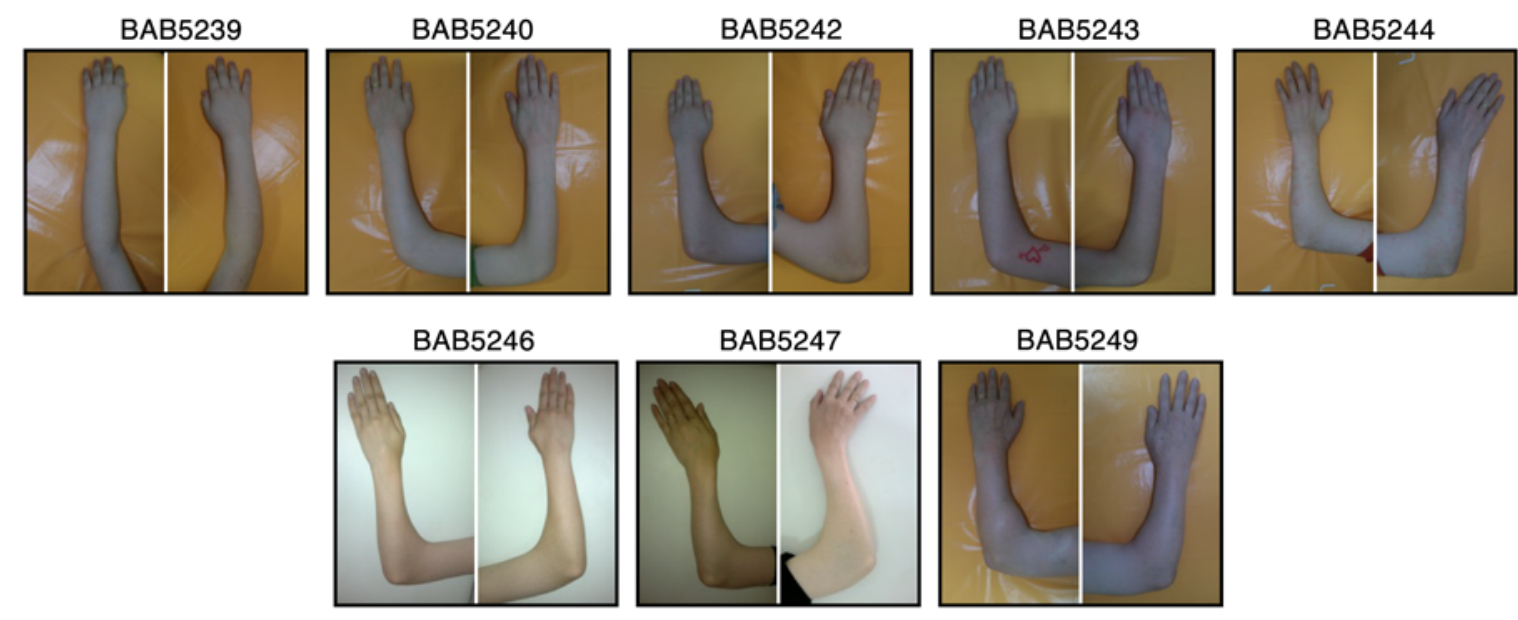

Figure 8. PSD3 variant showing an autosomal dominant inheritance identified in the patients with APS. (A) Sanger sequencing analysis showing the segregation result of PSD3 variant identified in family HOU2061. (B) Elbow photographs of the affected individuals.

utilized for both PCR amplification and Sanger sequencing. PCR reactions were performed following the protocols for HotStarTaq DNA Polymerase (QIAGEN).

$A O H$ and copy number variation (CNV) analysis. To examine $\mathrm{AOH}$ regions surrounding candidate variants, we calculated B-allele frequency using WES data as a ratio of variant reads to total reads. These data were then processed using the circular binary segmentation algorithm to identify $\mathrm{AOH}$ regions (72).

To identify heterozygous CNVs, we used WES data. WES data were processed using CoNIFER software (73) and HMZDelFinder (https:// github.com/BCM-Lupskilab/HMZDelFinder). HMZDelFinder is an in-house-developed algorithm implemented in the $\mathrm{R}$ programming language (R Core Team 2014, http://www.R-project.org). First, for every individual, we computed the total number of reads in each exon and normalized read-depth values (reads per kilobase per million [RPKM] mapped reads) using the utility provided with CoNIFER (73). Next, we identified homozygous deletions by analyzing exons for which the RPKM value was lower than 0.5. Then, low-quality samples (5\% of individuals with the highest number of deletions) were removed. Next, low-quality/common deletions were removed- if the frequency of a particular homozygous/hemizygous deletion was $\geq 0.5 \%$ in the whole cohort - and calls from consecutive exons were merged.

RPKM thresholds were determined based on the analysis of distribution of RPKM values in previously identified and confirmed homozygous deletions. Finally, we filtered out homozygous CNVs that did not overlap with larger $(\geq 1 \mathrm{~Kb})$ AOH regions. RPKM values were also used for further visualization of detected deletions.

Interaction network analysis. As a part of our approach to identify novel candidate genes, we performed interaction network analyses. The predicted interaction network had been based on 6 data sources, including coexpression, colocalization, pathways, physical interactions, predicted interactions, and shared protein domain data sources. Being predicted to be included in a potential interaction network with known disease genes may further support the novel gene association with the disease.

Study approval. This study was approved by the Institutional Review Board at Baylor College of Medicine. Informed consent was obtained from all subjects prior to enrollment in the project. Additionally, written consent was obtained from patients or patients' parents to publish patient photos. 


\section{Author contributions}

YB participated in study design, analyzed the WES data, and wrote the manuscript. EK, TH, and DP contributed to clinical assessment of the patients and WES analyses. ZCA and TG participated in computational and bioinformatics design and analysis. ZCA performed copy number variation and interaction network analyses. EOY, GAT, HA, DT, STB, AG, SI, AWEH, WLC, AK, TC, OOY, TY, $\mathrm{IAB}, \mathrm{NE}$, and $\mathrm{BT}$ participated in clinical evaluation of the patients and sample collection. MMA participated in DNA extraction, PCR validation, and figure production for the manuscript. SNJ, DMM, EB, and RAG organized the WES data analyses. JRL participated in study design, data organization, management and analyses, and writing of the manuscript. All coauthors reviewed the manuscript.

\section{Acknowledgments}

We thank the patients and their families who participated in this study. This work was supported in part by US NHGRI/NHLBI grant U54HG006542 to the Baylor-Hopkins Center for Mendelian Genomics and US NINDS grant R01NS058529 to J.R. Lupski. W.L. Charng is supported by CPRIT training Program RP140102, and T. Harel is supported by the T32 GM07526 Medical Genetics Research Fellowship Program.

Address correspondence to: James R. Lupski, Department of Molecular and Human Genetics, Baylor College of Medicine, One Baylor Plaza, Room 604B, Houston, Texas 77030, USA. Phone: 713.798.3723; E-mail:jlupski@bcm.edu.
1. Lowry RB, Sibbald B, Bedard T, Hall JG. Prevalence of multiple congenital contractures including arthrogryposis multiplex congenita in Alberta, Canada, and a strategy for classification and coding. Birth Defects Res A Clin Mol Teratol. 2010;88(12):1057-1061.

2. Hall JG. Arthrogryposis (multiple congenital contractures): diagnostic approach to etiology, classification, genetics, and general principles. Eur J Med Genet. 2014;57(8):464-472.

3. Filges I, Hall JG. Failure to identify antenatal multiple congenital contractures and fetal akinesia - proposal of guidelines to improve diagnosis. Prenat Diagn. 2013;33(1):61-74.

4. Haliloglu G, Topaloglu H. Arthrogryposis and fetal hypomobility syndrome. Handb Clin Neurol. 2013;113:1311-1319.

5. Bamshad M, Jorde LB, Carey JC. A revised and extended classification of the distal arthrogryposes. Am JMed Genet. 1996;65(4):277-281.

6. Hall JG, Reed SD, Greene G. The distal arthrogryposes: delineation of new entities - review and nosologic discussion. Am JMed Genet. 1982;11(2):185-239.

7. Beals RK. The distal arthrogryposes: a new classification of peripheral contractures. Clin Orthop Relat Res. 2005;(435):203-210.

8. Oldfors A. Hereditary myosin myopathies. Neuromuscul Disord. 2007;17(5):355-367.

9. Toydemir RM, Rutherford A, Whitby FG, Jorde LB, Carey JC, Bamshad MJ. Mutations in embryonic myosin heavy chain (MYH3) cause Freeman-Sheldon syndrome and Sheldon-Hall syndrome. Nat Genet. 2006;38(5):561-565.

10. Gurnett CA, et al. Myosin binding protein C1: a novel gene for autosomal dominant distal arthrogryposis type 1. Hum Mol Genet. 2010;19(7):1165-1173.

11. Sung SS, et al. Mutations in genes encoding fast-twitch contractile proteins cause distal arthrogryposis syndromes. Am J Hum Genet. 2003;72(3):681-690.

12. Sung SS, Brassington AM, Krakowiak PA, Carey JC, Jorde LB, Bamshad M. Mutations in TNNT3 cause multiple congenital contractures: a second locus for distal arthrogryposis type 2B. Am J Hum Genet. 2003;73(1):212-214.

13. McMillin MJ, et al. Mutations in ECEL1 cause distal arthrogryposis type 5D. Am J Hum Genet. 2013;92(1):150-156.
14. Dieterich K, et al. The neuronal endopeptidase ECEL1 is associated with a distinct form of recessive distal arthrogryposis. Hum Mol Genet. 2013;22(8):1483-1492.

15. Vogt J, et al. CHRNG genotype-phenotype correlations in the multiple pterygium syndromes. JMed Genet. 2012;49(1):21-26.

16. Kawira EL, Bender HA. An unusual distal arthrogryposis. Am JMed Genet. 1985;20(3):425-429.

17. McKeown CM, Harris R. An autosomal dominant multiple pterygium syndrome. JMed Genet. 1988;25(2):96-103.

18. Prontera P, Sensi A, Merlo L, Garani G, Cocchi G, Calzolari E. Familial occurrence of multiple pterygium syndrome: expression in a heterozygote of the recessive form or variability of the dominant form? Am JMed Genet A. 2006;140(20):2227-2230.

19. Hoffmann K, et al. Escobar syndrome is a prenatal myasthenia caused by disruption of the acetylcholine receptor fetal gamma subunit. Am J Hum Genet. 2006;79(2):303-312.

20. Morgan NV, et al. Mutations in the embryonal subunit of the acetylcholine receptor (CHRNG) cause lethal and Escobar variants of multiple pterygium syndrome. Am J Hum Genet. 2006;79(2):390-395.

21. Michalk A, et al. Acetylcholine receptor pathway mutations explain various fetal akinesia deformation sequence disorders. Am J Hum Genet. 2008;82(2):464-476.

22. McKie AB, et al. Germline mutations in RYR1 are associated with foetal akinesia deformation sequence/lethal multiple pterygium syndrome. Acta Neuropathol Commun. 2014;2(1):148.

23. Chong JX, et al. Autosomal-Dominant Multiple Pterygium Syndrome Is Caused by Mutations in MYH3. Am J Hum Genet. 2015;96(5):841-849.

24. Hall JG. Arthrogryposis multiplex congenita: etiology, genetics, classification, diagnostic approach, and general aspects. J Pediatr Orthop B. 1997;6(3):159-166.

25. Narkis G, Landau D, Manor E, Ofir R, Birk OS. Genetics of arthrogryposis: linkage analysis approach. Clin Orthop Relat Res. 2007;456:30-35

26. Hunter JM, et al. Review of X-linked syndromes with arthrogryposis or early contractures-aid to diagnosis and pathway identification. Am JMed Genet A. 2015;167A(5):931-973.

27. Drury S, et al. A novel homozygous ERCC5 truncating mutation in a family with prenatal arthrogryposis - further evidence of genotype-phenotype correlation. Am JMed Genet A. 2014;164A(7):1777-1783.

28. Fukumura S, et al. Compound heterozygous GFM2 mutations with Leigh syndrome complicated by arthrogryposis multiplex congenita. J Hum Genet. 2015;60(9):509-513.

29. Ravenscroft G, et al. Mutations of GPR126 are responsible for severe arthrogryposis multiplex congenita. Am J Hum Genet. 2015;96(6):955-961.

30. Wilbe M, et al. MuSK: a new target for lethal fetal akinesia deformation sequence (FADS). J Med Genet. 2015;52(3):195-202.

31. Tan-Sindhunata MB, et al. Identification of a Dutch founder mutation in MUSK causing fetal akinesia deformation sequence. Eur J Hum Genet. 2014; 23(9):1151-1157.

32. Alazami AM, et al. A novel syndrome of KlippelFeil anomaly, myopathy, and characteristic facies is linked to a null mutation in MYO18B. JMed Genet. 2015;52(6):400-404.

33. Pagnamenta AT, et al. Germline recessive mutations in PI4KA are associated with perisylvian polymicrogyria, cerebellar hypoplasia and arthrogryposis. Hum Mol Genet. 2015;24(13):3732-3741.

34. Fusco C, Frattini D, Salerno GG, Canali E, Bernasconi P, Maggi L. New phenotype and neonatal onset of sodium channel myotonia in a child with a novel mutation of SCN4A gene. Brain Dev. 2015;37(9):891-893.

35. Rienhoff HY Jr, et al. A mutation in TGFB3 associated with a syndrome of low muscle mass, growth retardation, distal arthrogryposis and clinical features overlapping with Marfan and Loeys-Dietz syndrome. Am JMed Genet A. 2013;161A(8):2040-2046.

36. Laquerriere A, et al. Mutations in CNTNAP1 and ADCY6 are responsible for severe arthrogryposis multiplex congenita with axoglial defects. Hum Mol Genet. 2014;23(9):2279-2289.

37. Graham JM Jr, et al. Cerebro-oculo-facio-skeletal syndrome with a nucleotide excision-repair defect and a mutated XPD gene, with prenatal diagnosis in a triplet pregnancy. Am J Hum Genet. 2001;69(2):291-300.

38. Gonzaga-Jauregui C, et al. Exome sequence analysis suggests that genetic burden contributes to phenotypic variability and complex neuropathy. Cell Rep. 2015;12(7):1169-1183. 
39. Esposito T, et al. Digenic mutational inheritance of the integrin alpha 7 and the myosin heavy chain 7B genes causes congenital myopathy with left ventricular non-compact cardiomyopathy. Orphanet J Rare Dis. 2013;8:91.

40. Yang $\mathrm{Y}$, et al. Molecular findings among patients referred for clinical whole-exome sequencing. JAMA. 2014;312(18):1870-1879.

41. Demir E, et al. Mutations in COL6A3 cause severe and mild phenotypes of Ullrich congenital muscular dystrophy. Am J Hum Genet. 2002;70(6):1446-1458.

42. Neveling K, et al. Mutations in BICD2, which encodes a golgin and important motor adaptor, cause congenital autosomal-dominant spinal muscular atrophy. Am J Hum Genet. 2013;92(6):946-954.

43. Markus B, Narkis G, Landau D, Birk RZ, Cohen I, Birk OS. Autosomal recessive lethal congenital contractural syndrome type 4 (LCCS4) caused by a mutation in MYBPC1. Hum Mutat. 2012;33(10):1435-1438.

44. Ha K, et al. MYBPC1 mutations impair skeletal muscle function in zebrafish models of arthrogryposis. Hum Mol Genet. 2013;22(24):4967-4977.

45. Dagoneau N, et al. Null leukemia inhibitory factor receptor (LIFR) mutations in Stuve-Wiedemann/Schwartz-Jampel type 2 syndrome. Am J Hum Genet. 2004;74(2):298-305.

46. Golomb E, et al. Identification and characterization of nonmuscle myosin II-C, a new member of the myosin II family. J Biol Chem. 2004;279(4):2800-2808.

47. Choi BO, et al. A complex phenotype of peripheral neuropathy, myopathy, hoarseness, and hearing loss is linked to an autosomal dominant mutation in MYH14. Hum Mutat. 2011;32(6):669-677.

48. Carim L, Sumoy L, Andreu N, Estivill X, Escarceller M. Cloning, mapping and expression analysis of VPS33B, the human orthologue of rat Vps33b. Cytogenet Cell Genet. 2000;89(1-2):92-95.

49. Epp N, Ungermann C. The N-terminal domains of Vps3 and Vps8 are critical for localization and function of the CORVET tethering complex on endosomes. PLoS One. 2013;8(6):e67307.

50. Gissen P, et al. Mutations in VPS33B, encoding a regulator of SNARE-dependent membrane fusion, cause arthrogryposis-renal dysfunction-cholestasis (ARC) syndrome. Nat Genet. 2004;36(4):400-404.

51. Feinstein M, et al. VPS53 mutations cause progressive cerebello-cerebral atrophy type 2 (PCCA2). J Med Genet. 2014;51(5):303-308.

52. Ben-Zeev B, et al. Progressive cerebellocerebral atrophy: a new syndrome with microcephaly, mental retardation, and spastic quadriplegia. JMed Genet. 2003;40(8):e96.

53. Cullinane AR, et al. Mutations in VIPAR cause an arthrogryposis, renal dysfunction and cholestasis syndrome phenotype with defects in epithelial polarization. Nat Genet. 2010;42(4):303-312.

54. Bernard G, et al. Mutations of POLR3A encoding a catalytic subunit of RNA polymerase Pol III cause a recessive hypomyelinating leukodystrophy. Am J Hum Genet. 2011;89(3):415-423.

55. Fontana M, et al. CMR-verified interstitial myocardial fibrosis as a marker of subclinical cardiac involvement in LMNA mutation carriers. JACC Cardiovasc Imaging. 2013;6(1):124-126.

56. Sarici D, Akin MA, Kara A, Doganay S, Kurtoglu S. Seckel syndrome accompanied by semilobar holoprosencephaly and arthrogryposis. Pediatr Neurol. 2012;46(3):189-191.

57. Wraith JE, et al. Mucopolysaccharidosis type II (Hunter syndrome): a clinical review and recommendations for treatment in the era of enzyme replacement therapy. Eur J Pediatr. 2008;167(3):267-277.

58. Andersen DH. Familial cirrhosis of the liver with storage of abnormal glycogen. Lab Invest. 1956;5(1):11-20.

59. Tang TT, et al. Neonatal hypotonia and cardiomyopathy secondary to type IV glycogenosis. Acta Neuropathol. 1994;87(5):531-536.

60. Bruno C, Cassandrini D, Assereto S, Akman HO, Minetti C, Di Mauro S. Neuromuscular forms of glycogen branching enzyme deficiency. Acta Myol. 2007;26(1):75-78.
61. Goebel HH, et al. Adult polyglucosan body myopathy. J Neuropathol Exp Neurol. 1992;51(1):24-35.

62. Moses SW, Parvari R. The variable presentations of glycogen storage disease type IV: a review of clinical, enzymatic and molecular studies. Curr Mol Med. 2002;2(2):177-188.

63. Bahler M. Myosins on the move to signal transduction. Curr Opin Cell Biol. 1996;8(1):18-22.

64. Mooseker MS, Cheney RE. Unconventional myosins. Annu Rev Cell Dev Biol. 1995;11:633-675.

65. Gorman SW, et al. The cloning and developmental expression of unconventional myosin IXA (MYO9A) a gene in the Bardet-Biedl syndrome (BBS4) region at chromosome 15q22-q23. Genomics. 1999;59(2):150-160.

66. Jin J, Chou C, Lima M, Zhou D, Zhou X. Systemic sclerosis is a complex disease associated mainly with immune regulatory and inflammatory genes. Open Rheumatol J. 2014;8:29-42.

67. Yang Y, et al. Clinical whole-exome sequencing for the diagnosis of mendelian disorders. $\mathrm{N} \mathrm{EnglJ}$ Med. 2013;369(16):1502-1511.

68. Lupski JR, et al. Exome sequencing resolves apparent incidental findings and reveals further complexity of SH3TC2 variant alleles causing Charcot-Marie-Tooth neuropathy. Genome Med. 2013;5(6):57.

69. Li H, et al. The Sequence Alignment/ Map format and SAMtools. Bioinformatics. 2009;25(16):2078-2079.

70. Wang K, Li M, Hakonarson H. ANNOVAR: functional annotation of genetic variants from high-throughput sequencing data. Nucleic Acids Res. 2010;38(16):e164.

71. Bainbridge MN, et al. Whole-genome sequencing for optimized patient management. Sci Transl Med.2011;3(87):87re3.

72. Olshen AB, Venkatraman ES, Lucito R, Wigler M. Circular binary segmentation for the analysis of array-based DNA copy number data. Biostatistics. 2004;5(4):557-572.

73. Krumm N, et al. Copy number variation detection and genotyping from exome sequence data. Genome Res. 2012;22(8):1525-1532. 